\title{
Zytologische und histologische Untersuchungen der Schweissdrüsen in menschlicher Achselhaut.
}

\author{
Zur Zytologie der apokrinen Schweissdrüsen in der \\ menschlichen Achselhaut.
}

\author{
Von \\ Kiyoshi Minamitani. \\ Aus dem Anatomischen Institut der Keio Universität zu Tokyo.
}

Mit 26 Textfiguren.

Inhalt.

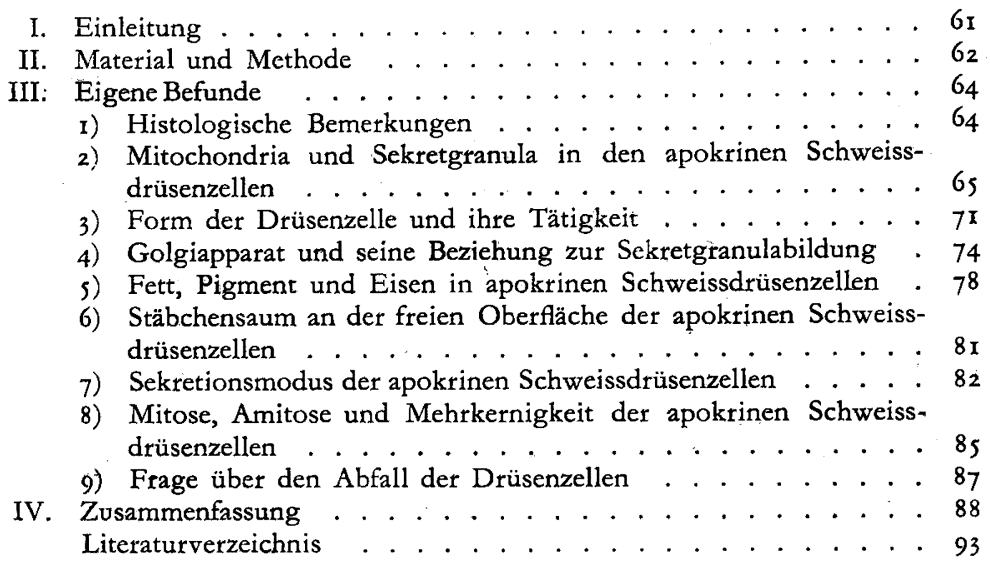

\section{Einleitung.}

In der vorgehenden Arbeit habe ich (194I) die Schweissdrüsen der menschlichen Achselhäute vorwiegend histologisch und zum Teil auch zytologisch sehr sorgfältig untersucht und bin dabei zu dem wichtigen Ergebnis gekommen, dass in menschlichen Achselhäuten ausser den typischen apokrinen und ekkrinen Schweissdrüsen noch atypische apokrine Drüsen und sogar gemischte Drüsen vorkommen können.

Ich habe hier eine eingehende zytologische Untersuchung der apokrinen 
Schweissdrüsen an denselben Achselhäuten vorgenommen, um die Sekretionsvorgänge in menschlichen apokrinen Schweissdrüsen und die dabei sichtbaren Veränderungen der Zytoplasmakomponente der Drüsenzellen näher zu studieren. Seit der epochemachenden Untersuchung von Schiefferdecker (1922) hat die histologische und zytologische Forschung der Schweissdrüsen kaum merkliche Fortschritte erfahren. Es gibt bis jetzt fast keine systematische zytologische Untersuchung der Schweissdrüsenzellen. Melczer (1935) hat zum ersten Mal den Golgiapparat der apokrinen Schweissdrüsenzellen in der menschlichen Achselhaut beschrieben, doch hat er die Beziehung zwischen dem Golgiapparat und der Sekretion nicht erörtert. Über die Mitochondrien und ihre Beziehung zu der Sekretion haben wir heute bei den apokrinen Schweissdrüsenzellen des Menschen nahezu keine Kenntnisse, obwohl neuerdings bei den tierischen Schweissdrüsen Ejima und Muto (1935) und Sawada (1940) die Mitochondrien der Drüsenzellen beschrieben haben. Die Pigmentkörnchen in den menschlichen apokrinen Schweissdrüsenzellen und ihre Eisen- und Fettreaktion sind neuerdings von einigen Autoren auseinandergesetzt worden ( $T$ alke (1903), Homma (1925), Herzenberg (1927), Richter (1933) u.a.). Jedoch haben die Autoren dabei die Beziehung zwischen den Pigmentkörnchen und den Sekretgranula nicht berücksichtigt.

In dieser Arbeit habe ich die Sekretionserscheinungen der apokrinen Schweissdrüsenzellen zytologisch eingehend studiert und den Golgiapparat, die Mitochondrien, Sekretgranula, Pigment- und Fettkörnchen und ihre Wechselbeziehungen bei der Sekretion erforscht. Hier habe ich mich in der zytologischen Untersuchung nur auf die „typischen “ apokrinen Schweissdrüsenzellen beschränkt (s. Minamitani (194I)). Ich habe in dieser Arbeıt die Achselhäute von Individuen mit Osmidrosis als Untersuchungsmaterial benutzt, weil bei solchen Achselhäuten, wie in der vorhergehenden Arbeit aufmerksam gemacht, die apokrinen Schweissdrüsen sich in lebhafter Tätigkeit befinden und man die apokrinen Drüsenzellen in verschiedenen Sekretionsstadien beobachten kann.

\section{Material und Methode.}

Das Untersuchungsmaterial bestand aus 14 im lebendfrischen Zustand fixierten Achselhäuten aus erwachsenen Menschen mit Osmidrosis ${ }^{1)}$, welche

I) Wie in der vorigen Arbeit angeführt, kommt der Osmidrosis axillae eine besondere Konstitution zu, bei welcher der Schweiss der Achselhöhle einen starken Geruch besitzt. In Japan wird dabei häufig die Achselhöhlenhaut chirurgisch entfernt, weil Japaner solchen Geruch nicht mögen. Bei Japanern kommt die Osmidrosis in etwa $9 \%-20 \%$ vor (Morioka (I933), Hirota (1939)). 
unter Lokalanästhesie durch subkutane Novocain-Injektion chirurgisch entfernt worden sind. Näheres über das Untersuchungsmaterial kann man in der Tabelle $\mathbf{r}$ finden. Sofort nach der chirurgischen Entfernung wurden die Achselhäute in kleine Stücke zerlegt und in Champy'sche, Levi'sche Regaud'sche Flüssigkeit und in Zenker-Formol eingetaucht. Die in Champy'scher Flüssigkeit fixierten Hautstücke wurden weiter nach Kolatchev mit $\mathrm{x} \%$ Osmiumsäure bei $35^{\circ} \mathrm{C}$ etwa $6-7$ Tage lang imprägniert, um den Golgiapparat darzustellen. Nach der Entwässerung mittels der aufsteigenden Alkoholreihe kamen die Hautstücke in Xylol, dann wurden sie in Paraffin eingebettet und in 4-5 $\mu$ dicke Serienschnitte zerlegt. Die Färbung geschah hauptsächlich mit Eisenhämatoxylin nach Heidenhain, zum Teil mit Anilinfuchsin-Aurantia nach Kull. Die mit Zenker-Formol und Regaudschem Gemisch fixierten Schnitte wurden ausserdem noch mit Hämatoxylin (Han sen)-Eosin gefärbt. Die nach Kolatch ev osmierten Schnitte wurden zum Teil ungefärbt und zum Teil mit Kull'scher Methode gefärbt beobachtet.

Tabelle I.

\begin{tabular}{|c|c|c|}
\hline Nr. & Alter & Geschlecht \\
\hline I & 32 & 今ิ \\
\hline 2 & 31 & $\delta$ \\
\hline 3 & 23 & $\delta$ \\
\hline 4 & 17 & 우 \\
\hline 5 & 25 & 우 \\
\hline 6 & 41 & 우 \\
\hline 7 & 20 & ช \\
\hline
\end{tabular}

\begin{tabular}{|c|c|c|}
\hline Nr. & Alter & Geschlecht \\
\hline 8 & 16 & 우 \\
\hline 9 & 24 & 우 \\
\hline Io & 24 & $\hat{\delta}$ \\
\hline II & 27 & \& \\
\hline 12 & 25 & $\delta$ \\
\hline $1_{3}$ & $3 \mathrm{I}$ & 우 \\
\hline $\mathrm{I} 4$ & 22 & 우 \\
\hline
\end{tabular}

Osmidrosis axillae ist nach heutigen Anschauungen keine Erkrankung, sondern eine besondere Konstitution. Bei den Individuen mit Osmidrosis sind die apokrinen Schweissdrüsen in Achselhaut in lebhafter Tätigkeit, so dass man dort die zytologischen Veränderungen der apokrinen Schweissdrüsenzellen nach den verschiedenen Sekretionszuständen gut verfolgen kann. Deshalb habe ich in der vorliegenden zytologischen Untersuchung die Achselhäute von Individuen mit Osmidrosis als Untersuchungsmaterial gewählt (s. Minamitani (1941)).

Hier spreche ich Herrn Prof. Dr. Yokoyama und Dozent Dr. Kaneko der dermatologischen Klinik der Keio Universität für die freundliche Hilfe bei Ansammlung des Untersuchungsmaterials meinen herzlichsten Dank aus. 


\section{Eigene Befunde.}

\section{Histologische Bemerkungen.}

Die Histologie der Achselhaut habe ich schon in der vorigen Arbeit beschrieben. Die Achselhaut von Individuen mit Osmidrosis enthält immer zahlreiche grosse apokrine Schweissdrüsen, welche sich von der Lederhaut bis zum subkutanen Bindegewebe ausbreiten, so dass man in jedem senkrechten Schnitt des kleineren Hautstückes gewöhnlich zahlreiche apokrine Schweissdrüsen finden kann. Die Drüsentubuli sind im allgemeinen dick, indem sie.am häufigsten von hoch zylindrischen Drüsenzellen umgeben sind; die Drüsentubuli mit kubischen oder mehr platten Drüsenzellen sind bei der Osmidrosis verhältnismässig selten. Die Querschnitte der Drüsenzellen sind 5-6 seitig (Fig. 7); die sogenannten zylindrischen Drüsenzellen stellen also 5-6 seitige Prismen dar. Die Drüsentubuli sind von bindegewebiger Membrana propria und glatten Muskelfasern umhüllt. Die Membrana propria besteht aus feinen zirkulären Bindegewebsfibrillen, deren innerste Schicht bandartige Fibrillenbündel bildet und die longitudinal verlaufenden glatten Muskelfasern wie Reifen zusammenfasst ; dieses Bündel tingiert sich bei Eisenhämatoxylinfärbung intensiv (Reifenfasern). Die glatten Muskelfasern ziehen immer longitudinal zum Drüsentubulus; beim Querschnitt des letzteren trifft man ihre Querschnittbilder. Die Muskelfasern berühren die Basalfläche der Drüsenzellen unmittelbar, springen in die letztere vor. Im Querschnitt des Drüsentubulus erweisen sich die Muskelfasern als kuppelartige Bildungen, welche innerhalb des Basalteils der Drüsenzellen hineinragen. An ihrer Spitze findet man oft den rundlichen Kern der Muskelfaser vor. Der Kern der Muskelfaser ist länglich oval oder spindelförmig, dessen Längsachse derselben der Muskelfasern parallel steht. Er liegt immer auf der inneren Fläche der Muskelfaser.

Die Drüsenzellen stehen auf der glatten Muskelfaserschicht, so dass ihre Basalfläche sich unmittelbar mit der letzteren verbindet. Die Anordnung der apokrinen Drüsenzellen ist regelmässig, indem sie im allgemeinen weites Drüsenlumen umgebend einschichtig gereiht sind. Solche regelmässige Anordnung der Drüsenzellen ist hauptsächlich auf die regelmässige Gestalt derselben zurückzuführen. Die in einem Querschnitt des Drüsentubulus zu findenden Drüsenzellen sind im grossen ganzen gleich hoch und gleich gestaltet; daraus kann man èrwarten, dass die Drüsenzellen in einem Querschnitte des Drüsentubulus sämtlich in gleichem Funktionszustand sich befinden. Zwischen den freien Oberflächen der Drüsenzellen kommt die Schlussleiste vor, doch werden zwischenzellige Sekretkanälchen bei apokrinen 
Schweissdrüsen nicht wahrgenommen.

Die apokrinen Schweissdrüsenzellen sind im allgemeinen gross; ihre Form ist verschieden, doch findet man hochzylindrische Drüsenzellen am häufigsten.

Der Kern kommt in der Regel einfach, selten zweifach vor, wie unten näher auseinandergesetzt wird. Er liegt bei den zylindrischen Zellen meistens unterhalb der Mittelhöhe der Zelle. Er ist in der Regel rundlich geformt und sieht hell aus. An den Kernen der apokrinen Schweissdrüsenzellen kann man im ganzen Verlauf der apokrinen Sekretion fast keine merkliche Veränderungen bemerken. In der Nähe der Kernmitte kommt gewöhnlich ein grosses, rundliches Kernkörperchen vor, welches zuweilen eine oder zwei viel kleinere Nebennukleolen begleitet. Die Grösse des Kerns beträgt bei zylindrischen Drüsenzellen durchschnittlich ca. $8 \mu$, die des Kènkörperchens durchschnittlich $2.2 \mu$; bei niedrigen Drüsenzellen durchschnittlich ca. 7.5 $\mu$ und die des Kernkörperchens durchschnittlich ca. $2 \mu$.

Das Zytoplasma der apokrinen Schweissdrüsenzellen ist dicht. gebaut und sieht dunkel aus. Es färbt sich bei Hämatoxylin-Eosin-Färbung mit Eosin gut, bei Eisenhämatoxylin-Färbung nach Heidenhain dunkel. Bei der Osmidrosis enthalten die apokrinen Schweissdtrüsenzellen zum grössten Teil zahlreiche Sekretgrạnula.

\section{Mitochondria und Sekretgranula in den apokrinen Schweissdrüsenzellen.}

Bei den apokrinen Drüsenzellen der Achselhaut stehen Mitochondrien und Sekretgranula in einer innigen Beziehung, so kann man beide nicht voneinander getrennt erwähnen. Die Arbeiten, welche Mitochondrien sowie Sekretgranula und ihre Wechselbeziehung in den apokrinen Schweissdrüsen näher beschreiben, sind bisher kaum zu finden. Die fuchsinophile oder acidophile Granula, welche von Mislawsky (1909a) und Brinkmann (I9II) bei den Schweissdrüsenzellen von Tieren bemerkt wurden, scheinen Mitochondrien und Sekretgranula dieser Zellen zu vertreten. 'Nach Mislawsky wachsen die fuchsinophilen Granula, verlieren ihre Färbbarkeit und wandeln in das Sekret um. Nach Brinkmann stammen sie von Basalfilamenten ab, fliessen im apikalen Teil der Zelle zu grösseren kugligen Granula zusammen. Nicolas, Regaud und Favre (I9I2) haben Mitochondrien in apokrinen und ekkrinen Schweissdrüsenzellen untersucht und kamen zu den Ergebnissen, dass die Mitochondrien im Zytoplasma verstreute Stäbchen oder Körnchenkette darstellen, und dass zwischen den Mitochondrien und Sekretgranula eine genetischen Wechselbeziehung vor- 
handen ist. Nach ihren Untersuchungen ist die Menge der Sekretgranula beim zahlreichen Vorkommen der Mitochondrien klein, und beim geringeren Vorkommen gross; also wandeln die Mitochondrien in die Sekretgranula um. Nach Hoepke (1927) treten bei Beginn der Sekretion der apokrinen Schweissdrüsenzellen einige Granula über dem Kern auf, die immer mehr an Zahl zunehmen, und dadurch die bisher niedrige Zelle in die Zylinderform zwingen. Nach ihm entstehen mehr oder weniger grosse Vakuolen wahrscheinlich durch Verflüssigung der Granula, die mit der Zunge (Sekretfortsatz) abgeschnürt werden. Schaffer (1927) und Herzenberg (1927) haben bei den apokrinen Schweissdrüsen der menschlichen Achselhaut Sekretgranula beschrieben, welche nach Herzenberg starklichtbrechend, goldgelb und eosinophil sind und im Apikalteil der Zelle gefunden werden. Nach Schaffer ist die Angabe fraglich, dass die Sekretgranula mit den Mitochondrien genetisch etwas $\mathrm{zu}$ tun haben. Neuerdings haben Ejima und Muto (1935) und Sawada (1940) die Mitochondrien der Schweissdrüsenzellen der Säugetiere beschrieben. Nach den ersteren Autoren sind die Mitochondrien zahlreich über dem Kern zu finden, welche feine Granula, Stäbchen und Fäden darstellen. Nach dem letzteren Autor enthalten kubische und platte apokrine Drüsenzellen in der Umgebung des Kerns faden- und stäbchenförmige Mitochondrien, während die zylindrischen Drüsenzellen in ihrem apikalen Teile kürzere Stäbchen oder verdoppelte Körnchen, in den übrigen Teilen vorwiegend leicht gebogene längere Fäden enthalten. Nach seiner Beobachtung werden im Drüsenlumen, vermengt mit einer amorphen Masse, oft verdoppelte und isolierte Körnchen vorgefunden, welche wahrscheinlich von den abgeschnürten und zerfallenen Zellkuppeln herstammen.

Nach meiner eigenen Untersuchung scheinen zwischen Mitochondrien und Sekretgranula innige genetische Wechselbeziehung zu bestehen, wie von Nicolas, Regaud und Favre angenommen. Die Drüsenzellen, welche zahlreiche Sekretgranula enthalten, führen wenige Mitochondrien oder scheinen gar keine zu führen. Dagegen findet man bei den Drüsenzellen, welche wenige Sekretgranula oder gar keine besitzen, zahlreiche Mitochondrien; in der Fig. I begegnet man solche Drüsenzellen. Die linke Zelle in dieser Figur enthält gar keine Sekretgranula, die rechte im apikalen Teil wenige. Die Mitochondrien sind stäbchen-, fadenförmig und granulär; die stäbchenförmigen Mitochondrien überwiegen an Zahl, die fadenförmigen sind leicht gebogen hauptsächlich oberhalb des Kerns vorhanden. Beide Formen sind im grossen ganzen der Längsachse der Zelle parallel gerichtet. Unter den stäbchenförmigen Mitochondrien findet man hantelförmige oder verdoppelt körnchenförmige, welche infolge der Verdickung der beiden 
Enden der stäbchenförmigen Mitochondrien zustandezukommen scheinen. Es wird oft bemerkt, dass die fadenförmigen Mitochondrien in die Körnchenkette übergehen, indem sie einige Verdickungen führen. Die ringförmigen Gebilde, welche man in den Zellen der Fig. I findet, stellen wahrscheinlich die besondere Form der Mitochondrien dar.

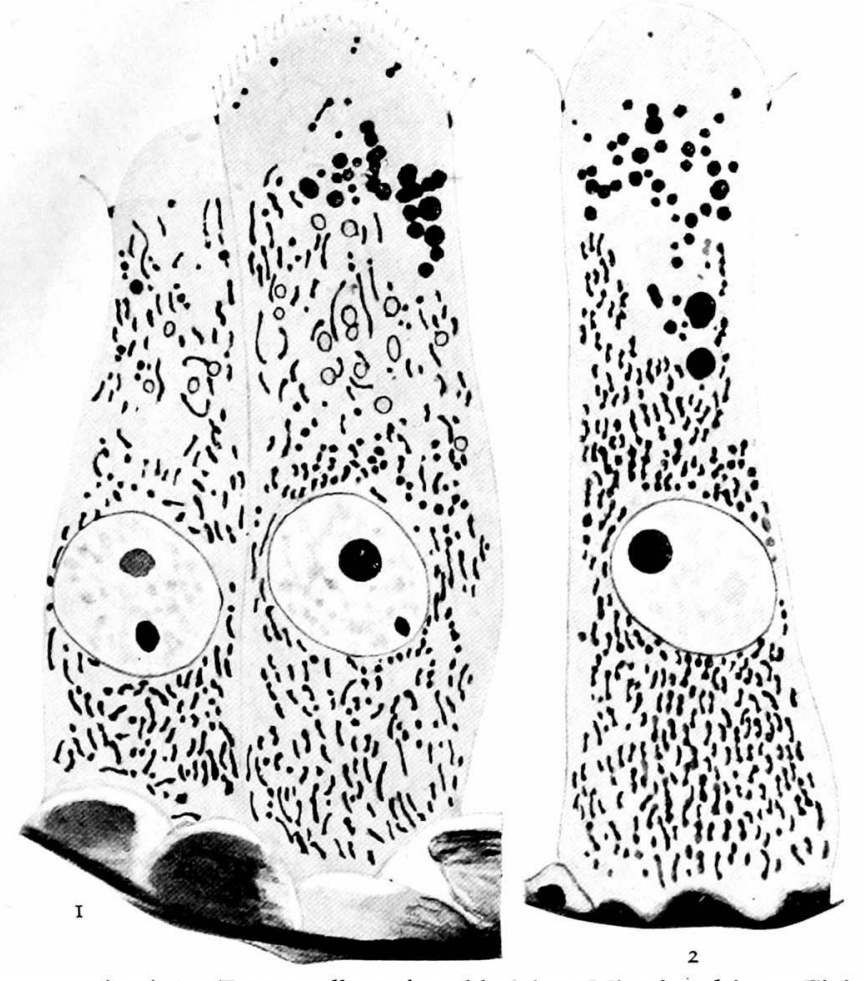

Fig. 1-2. Apokrine Drüsenzellen mnit zahlreichen Mitochondrien. Fixiert mit Levi's Gemisch, gefärbt mit Eisenhämatoxylin nach $\mathrm{Heidenhain.}$ Zeiss Apochr.-Jmm. 2 mm. n. A. 1, 3 Komp.-ok. 12.

Die Verteilung der Mitochondrien ist im grossen ganzen gleichmässig, aber im apikalen Teil ist sie viel lockerer als im basalen Teil, besonders trifft man oberhalb des Kerns eine rundliche Zone an, wo die Mitochondrien sehr spärlich sind; diese Zone, wie unten näher erwähnt wird, ist nichts anders als das Golgifeld. Ausserdem findet man im Spitzenteil der Zelle eine relativ breite, mitochondrienfreie Zone, die, wie in der vorigen Arbeit schon aufmerksam gemacht, eine wichtige Beschaffenheit der apokrinen Schweissdrüsenzelle darbietet.

Die eben beschriebene, durch zahlreiche Mitochondrien gefüllte Drüsenzelle ist äusserst selten vorzufinden, so dass man annehmen muss, dass dieses 
Stadium im Sekretionszyklus der apokrinen Schweissdrüsenzelle sehr schnell verläuft. Man muss hier ausserdem im Auge behalten, dass diese sekretgranulafreien, und durch Mitochondrien gefüllten Drüsenzellen gar nicht niedrig, sondern hochzylindrisch sind, wie durch Sekretgranula gefüllte Zellen.

Die in der Fig. 2 wiedergegebene hochzylindrische Drüsenzelle, welche in ihrem Apikalteil verschieden grosse Sekretgranula in kleiner Zahl enthält, hat auch zahlreiche Mitochondrien, welche im ganzen Zytoplasma gleichmässig dicht verteilt sind, das Golgifeld und Endabschnitt der Zelle ausgenommen. Hier stellen aber Mitochondrien zum grössten Teil doppelte Körnchen (Hantelform) oder Körnchenketten dar; die Verdickungen sind dabei deutlich. Diese Zellen sind auch sehr selten zu bemerken.

Bei der in der Fig. 3 abgebildeten Drüsenzelle ist das Zytoplasma, das Golgifeld und den Drüsenlumen zugewandten Endabschnitt ausgenommen, mit kleinen Körnchen dicht gefüllt, welche im grossen ganzen etwas grösser als die granulären Mitochondrien sind. Es ist schwer zu entscheiden, ob diese Granula granuläre Mitochondrien oder kleine, jüngste Sekretgranula sind. Hier können wir kaum mehr stäbchen-, fadenförmige und hantelförmige sowie perlschnurartige Mitochondrien vorfinden. Bei näherer Beobachtung erkennt man, dass die Granula oft in Granulakette oder doppelte Granula angeordnet sind. Im apikalen Teil dieser Zelle befinden sich grössere Granula, welche mit Sicherheit die Sekretgranula sind. Zwischen diesen grösseren apikalen Sekretgranula und den kleinen Granula werden Übergänge wahrgenommen.

Wenn man nun die Zellen in der Fig, 1,2 und 3 vergleicht, so versteht man ohne weiteres, dass die Mitochondrien in Form von Stäbchen und Fäden in Doppelkörnchen und Körnchenkette übergehen und dann sich in einzelne kleine Granula umwandeln, welche unter allmählicher Zunahme ihrer Grösse zu den Sekretgranula werden. Solche Vorgänge kommen im ganzen Zytoplasma nahezu gleichzeitig vor, doch findet man gewöhnlich die Sekretgranula zuerst im apikalen Teil der Zelle oberhalb des Golgifeldes vor.

Bei den in der Fig. 4 und 5 wiedergegebenen Drüsenzellen werden im basalen und juxtanukleären Abschnitt des Zytoplasma, nämlich unterhalb des Golgifeldes zwischen den feinen, von Mitochondrien abstammenden Granula zahlreiche grössere Granula wahrgenommen, welche nun mit aller Sicherheit als Sekretgranula bezeichnet werden können, während die ersteren sich von den granulären Mitochondrien kaum unterscheiden lassen. Im Zytoplasma dieser Zellen bemerkt man ausserdem noch die Mitochondrien in Form von Stäbchen, Doppelkörnchen und Körnchenkette und zwischen 
den feinen Granula und Sekretgranula alle Übergänge. Also geht bei diesen Zellen noch Neubildung der Sekretgranula vor sich.

Im apikalen Abschnitt dieser Zellen oberhalb des Golgifeldes befindet sich eine Anhäufung der gröberen Sekretgranula, die wieder verschieden gross sind; bei der Zelle in Fig. s findet man dort ausserordentlich grosse Granula vor.

Golgifeld stellt ein rundliches Feld dar, wo man gewöhnlich nur spärliche Granula antrifft (Fig. 3, 4, 5).

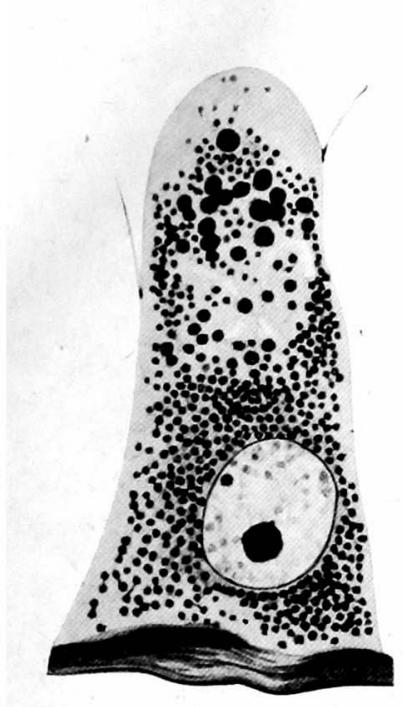

3

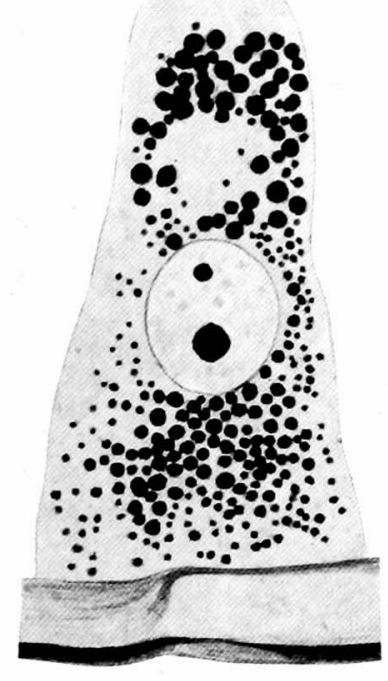

4

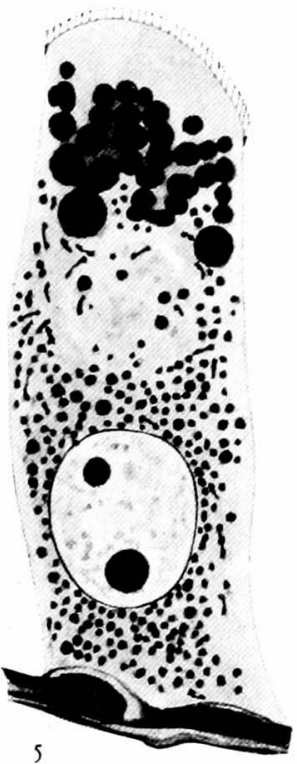

Fig. 3-5. Apokrine Drüsenzellen mit verschieden grossen Sekretgranula Fixierung, Färbung und Vergrösserung wie bei Fig. I-2.

Das Zytoplasma der in der Fig. 6 abgebildeten hochzylindrischen Zelle ist durch zahlreiche grössere Sekretgranula ausgefüllt; die Mitochondrien sind in der Basis der Zelle ganz spärlich vorhanden. Die in dem Apikalteil, das Golgifeld umgebend vorhandenen Sekretgranula sind im allgemeinen von besonderer Grösse. Zwischen ihnen treten spindelförmige Granula auf; solche besondere Granula trifft man oft in den apokrinen Drüsenzellen der menschlichen Achselschweissdrüsen an; ihre Genese ist mir unklar, sie gehören höchstwahrscheinlich den Sekretgranula an.

Die in der Fig. 3, 4, 5 und 6 gezeichneten, mit zahlreichen Granula gefüllten Drüsenzellen kommen bei den apokrinen Schweissdrüsen der Achselhaut mit Osmidrosis am häufigsten vor ; man kann sogar sagen, dass die apokrinen Schweissdrüsen dabei fast ausschliesslich aus solchen Drüsenzellen zusam- 
mengesetzt sind. Ich möchte diese Drüsenzellen als "Stapelzellen“ oder "Granulazellen" bezeichnen. Die Grösse der Sekretgranula in Granulazellen kann in gewissem Masse variieren und nach den einzelnen Zellen verschieden sein, doch führen sie immer im apikalen Abschnitt des Zytoplasma, zum grössten Teil oberhalb des Golgifeldes, zum Teil auch in der Umgebung desselben grössere Sekretgranula, wie oben schon erwähnt. Diese apikalen, gröberen Sekretgranula scheinen nach meiner Meinung die reifen Sekretgranula zu sein. Sie färben sich bei Eisenhämatoxylinfärbung nach Heidenhain gewöhnlich stärker als übrige Sekretgranula, sind gegen der Differenzierung mit Eisenalaun viel resistenter, wie aus Fig. 19, 20 und 2I zu ersehen ist. Sie werden bei Hämatoxylin(Hansen)-Eosinfärbung
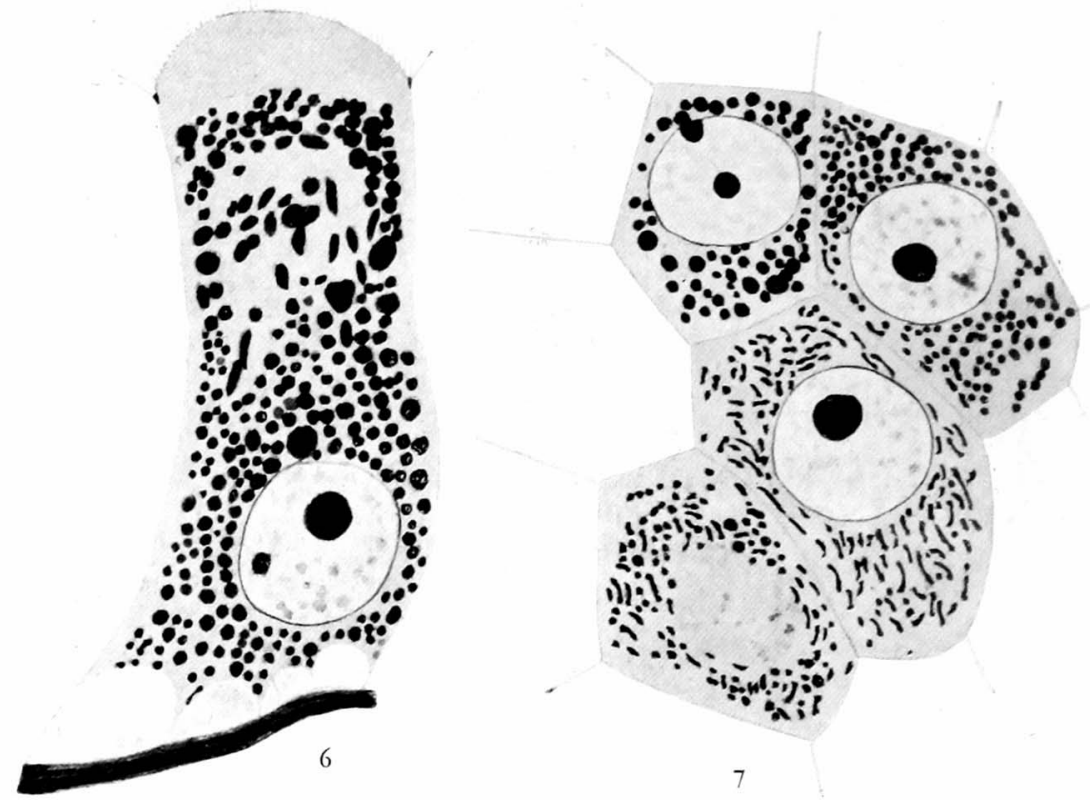

Fig. 6-7. Apokrine Drüsenzellen. 6. Drüsenzelle mit gröberen Sekretgranula. 7. Querschnitte der Drüsenzellen in der Höhe des Kerns. Fixierung, Färbung und Vergrösserung wie bei Fig. I u. 2.

meistenfalls mit Eosin rötlich, gleich wie die übrigen Sekretgranula. Bei Anilinfuchsin-Aurantiafärbung nach $\mathrm{Kull}$ tingieren sich aber die apikalen Sekretgranula mit etwas anderem Farbton als die übrigen Granula; sie färben sich dabei dunkelrötlich, während die letzteren sich rötlich anfärben (Fig. IO, II, I2). Daraus geht natürlich hervor, dass diese apikalen Sekretgranula chemisch von den übrigen verschieden zu sein scheinen. Wie unten näher erwähnt, lokalisieren sich Fett und Pigment an ihnen. Man kann 
also schliessen, dass die im basalen und juxtanukleären Abschnitt der Zelle befindlichen. Sekretgranula allmählich reif werden und sich im apikalen Abschnitt der Zelle ansammeln.

Wir können hier als Eigentümlíchkeiten der apokrinen Schweissdrüsenzellen der menschlichen Achselhaut zwei wichtige Befunde angeben; erstens ist die Verflüssigung der reifen Sekretgranula nicht wahrzunehmen, so dass wir hier eine alveoläre Struktur des Zytoplasma während des ganzen Sekretionszyklus nicht bemerken können. Zweitens erreichen die Sekretgranula nicht die freie Oberfläche der Zelle, indem sich zwischen der freien Oberfläche der Zelle und der Anhäufung der reifen apikalen Sekretgranula immer eine granulafreie, dicht gebaute Zytoplasmaschicht mit einer beträchtlichen Dicke befindet (s. oben).

Diese zwei Eigentümlichkeiten scheinen mit der apokrinen Sekretion in einer innigen Beziehung zu stehen und werden unten bei der Erörterung des Sekretionsmodus der apokrinen Schweissdrüsenzellen näher erwähnt.

\section{Form der Drüsenzellen und ihre Tätigkeit.}

Von den Autoren, welche die apokrinen Schweissdrüsenzellen histologisch untersucht haben, sind die Drüsenzellen oft in „tätige Drüsenzellen“ und ,ruhende Drüsenzellen" eingeteilt worden. Talke (1903) hat die apokrinen Schweissdrüsenzellen der menschlichen Achselhaut in ,dunkle“ und „helle Zellen“ eingeteilt. Die erstere ist hoch und breit und seiner Ansicht nach sezernierende Zelle, welche nach der Entleerung in die helle Zelle übergeht; die letztere vertritt nach seiner Ansicht die ruhende Zelle. Mis lawsky (I909) hat bei seiner Untersuchung der Glandula mandibularis superior von Kaninchen die apokrinen Drüsenzellen in kubische oder niedrig zylindrische Zellen und hochzylindrische eingeteilt; nach seiner Meinung bilden die ersteren die ruhenden, die letzteren die tätigen Drüsenteile. Er nimmt an, dass die hochzylindrischen 'Zellen sich nach Wiederholung des Sekretionszyklus erschöpfen und in die niedrigen, ruhenden Zellen übergehen, welche aber in eine neue Sekretionstätigkeit eintreten können. Holmgren (1922) hat auch die Drüsenzellen der menschlichen Achselschweissdrüse in Filtrationszellen und Zellen mit blasenförmiger Sekretion eingeteilt, doch gehören die ersteren, wie von $\mathrm{S} c h$ affer (1927) kritisiert, zu den ekkrinen Drüsenzellen, weil sie zwischenzellige Sekretröhrchen besitzen. Wie ich in der vorigen Untersuchung betont habe, besitzen die apokrinen Schweissdrüsenzellen nie solche Vorrichtung. Neuerdings hat Morioka (1935) bei der menschlichen Achselschweissdrüse die kubischen bis zylindrischen Drüsenzellen als tätigende, die platten als ruhende Zelle bezeichnet. 
Aus oben zitierten Arbeiten geht hervor, dass hochzylindrische Drüsenzellen tätige Zellen der apokrinen Schweissdrüsen sein sollen. Ich habe auch oben bei den zylindrischen Drüsenzellen der menschlichen Apokrinschweissdrüsen lebhafte Sekretgranulabildung auf Kosten der Mitochondrien gesehen und bei solchen Zellen weiter die apokrine Sekretion unter Bildung der kuppelförmigen Sekretfortsätze erkannt (s. unten). Also schliesse ich mich der Meinung der obigen Autoren an, dass die hochzylindrischen Drüsenzellen die lebhaft tätigen Zellen sein sollen. Die Tatsache, dass die Drüsentubuli der apokrinen Achselschweissdrüsen von Japaner mit Osmidrosis vorübergehend aus solchen hochzylindrischen Drüsenzellen zusammengesetzt sind, weist natürlich hin, dass bei der Osmidrosis die apokrinen Schweissdrüsen der Achselhaut lebhaft tätig sind, wie ich schon in der vorgehenden Arbeit berichtet habe.
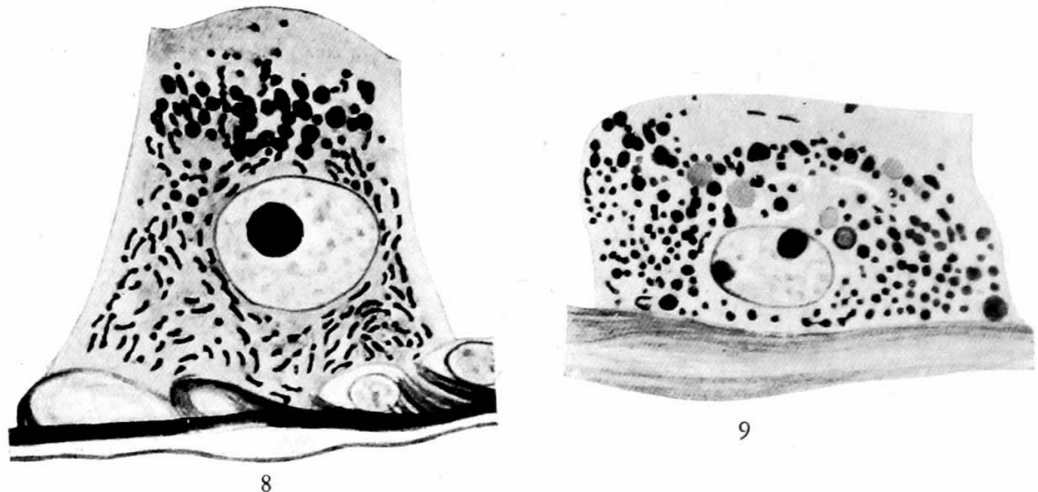

Fig. 8-9. Niedrige apokrine Drüsenzellen mit Mitochondrien und Sekretgranula. Fixierung, Färbung und Vergrösserung wei bei Fig. I u. 2.

Bei den niedrigen kubischen Drüsenzellen wurde festgestellt, dass sie auch dieselbe Sekretgranulabildung auf Kosten der Mitochondrien wie bei den zylindrischen Drüsenzellen aufweisen, wie in der Fig. 8 und 9 wiedergegeben; wir finden im apikalen Abschnitt des Zytoplasma die Anhäufung der reifen, gröberen Sekretgranula vor. Ich konnte weiter bei diesen niedrigen Drüsenzellen oft bemerken, dass sie von ihrer freien Oberfläche die kuppelförmigen Sekretfortsätze ins Drüsenlumen abschicken und die apokrine Sekretion entfalten. Daraus darf ich schliessen, dass die niedrigen Drüsenzellen durch die Stapelung der Sekretgranula nicht in die hochzylindrischen Zellen umwandeln, sondern sie im ganzen Verlauf des Sekretionszyklus ihre Gestalt kaum verändern.

Bei der Beobachtung der Sekretgranulabildung in den hochzylindrischen Zellen haben wir schon bemerkt, dass sie in dem durch zahlreiche Mitochon- 
drien gefüllten, die Sekretgranula fast vollkommen entbehrten Stadium schon hochzylindrisch sind. Weiter erkennen wir bei den in der Fig. 20 und $2 \mathrm{I}$ links abgebildeten hochzylindrischen Drüsenzellen, dass die Gestalt der Drüsenzellen sich nach der Abtrennung der Sekretfortsätze kaum verändert.

Auf Grund der obigen Befunde entsteht die Annahme, dass die zylindrischen und niedrigen Zellen die besonderen Zellformen vertreten, welche bei der Sekretion selbständig funktionieren und durch Veränderung der Gestalt infolge Erschöpfung oder Anhäufung der Sekretgranula ineinander nie übergehen, im Gegensatz zur Angabe von Mis law sky und Hoepke (1927). Hoepke hat, wie oben zitiert, angenommen, dass die niedrige Zelle durch Zunahme der Granula in die Zylinderform umwandelt.

Beobachtet man weiter eingehend die Zellen in Fig. 20 und $2 \mathrm{I}$, so erkennt man, dass die Drüsenzellen nach der Abtrennung der Sekretfortsätze noch die reifen Sekretgranula reichlich enthalten. Diese Tatsache spricht wohl davon, dass die einen Sekretionszyklus vollendeten Zellen weiter kontinuierlich apokrine Sekretion wiederholen können. Also kann man annehmen, dass auf diese Weise die hochzylindrischen Drüsenzellen, wie von $\mathrm{M}$ is law s ky angenommen, infolge Wiederholung der apokrinen Sekretion ganz allmählich erschöpfen und in kubische Zellen umwandeln. Gleiche Vorgänge kann auch bei den kubischen Drüsenzellen angenommen werden; dabei entstehen, schliesslich platte Zellen. Nach dieser Annahme gehen hochzylindrische Drüsenzellen durch wiederholte Sekretion schliesslich in platte Zellen über, wie von Mislawsky angenommen.

Ich habe in dieser Arbeit die von den platten Drüsenzellen zusammengesetzten Drüsentubuli oft bemerkt; die Sekretionsfähigkeit solcher platten Drüsenzellen ist fraglich, weil ich bei ihnen die Bildung der Sekretfortsätze nicht wahrgenommen habe. Sie scheinen also wahrscheinlich ruhende Drüsenzellen darzustellen. Doch führen sie immer im der Drüsenlichtung zugekehrten Abschnitt die gröberen Sekretgranula in wechselnder Menge.

Aus obigen Ergebnissen kann ich hier aber mit aller Sicherheit angeben, dass die hochzylindrischen Drüsenzellen am lebhaftesten sezernierende Zellen, die kubischen ebenso sekretionsfähige, aber die platten ruhende, nicht sezernierende sein sollen, und dass die reifen, gröberen Sekretgranula aber bei allen Zellformen immer enthalten sind.

Über die Beziehung zwischen diesen Zellformen kann man hier nichts Sicheres äussern, einerseits aber annehmen, dass die hochzylindrischen Zellen, wie oben angegeben, durch Wiederholung der Sekretion in die kubischen und dann in die platten übergehen, nämlich, die drei Zellformen die verschiedenen Funktionszustände ein und derselben Drüsenzelle darstellen; anderseits kann man schliessen, dass sie besondere Zellformen sind und 
im ganzen Sekretionszyklus als solche funktionieren, ohne dass sie durch Veränderung der Zellenhöhe ineinander übergehen.

\section{Golgiapparat und seine Beziehung zur Sekretgranulabildung.}

Bis zur Arbeit von Melczer (1935) ist es den Autoren nicht gelungen, den Golgiapparat der apokrinen Schweissdrüsenzellen positiv nachzuweisen. Bergen (1904) hat zuerst in den hochzylindrischen, apokrinen Schweissdrüsenzellen der menschlichen Achselhaut zwischen Kern und freier
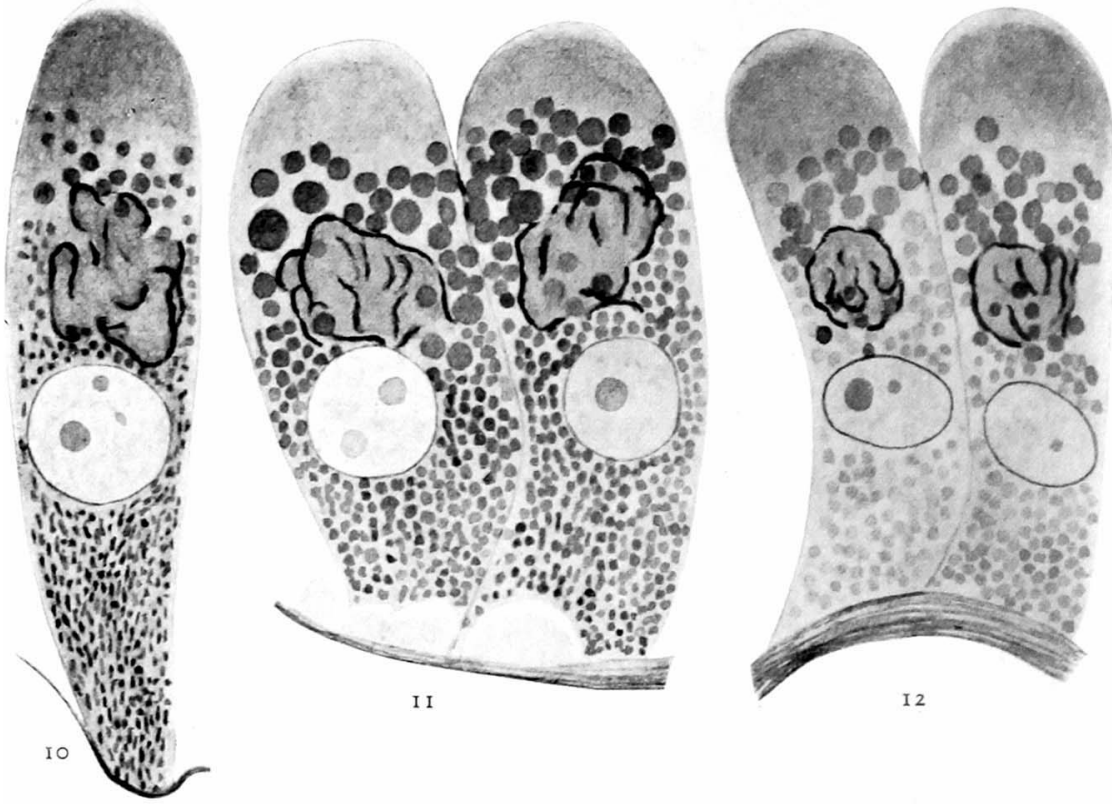

Fig. 10-1 2. Golgiapparat der apokrinen Drüsenzellen mit Mitochondrien (besonders in Fig. Io) und verschieden grossen Sekretgranula. Osmiumimprägnationsmethode nach Kolatchev, gefärbt nach Kull. Vergrösserung wie beı Fig. I u. 2.

Oberfläche ein geschlossenes Kanälchensystem dargestellt, welches aus geschlängerten, miteinander vereinigenden Kanälchen zusammengesetzt worden ist. Er hat angenommen, dass dieses Kanälchensystem in den Schweissdrüsenzellen höchstwahrscheinlich das Negativ eines Golgi'schen Binnennetzapparates darstellen könne. Ihm gelang es dabei nicht, mit der Osmiumimprägnationsmethode den Golgiapparat positiv nachzuweisen. Das gleiche Kanälchensystem wurde darauf in den apokrinen Schweissdrüsenzellen von Brinkmann (I9I I), Schaffer (I927) Stamm (zit. nach Schaffer) u.a. gefunden. Melczer (1935) hat erst überhaupt mit der Kopschschen Methode den Golgiapparat in den apokrinen Schweissdrüsenzellen der 
menschlichen Achselhaut und Haut der After- und Schamgegend positiv dargestellt. Nach seinem Ergebnis gehören die Golgiapparate der apokrinen Schweissdrüsenzellen, im Gegensatz zu den von ihm beschriebenen Apparaten der ekkrinen Schweissdrüsenzellen, nach der Hirs chle r'schen Terminologie zu dem komplexen Typus. Also fand er bei den hochzylindrischen Zellen in der oberhalb des Kerns befindlichen Plasmazone dreidimensionales Netz, welches aus den 4-ro Strängen, Golgikomponenten, besteht. Er hat weiter festgestellt, dass bei dem mit den Golgiapparat nicht konservierenden Fixierungsflüssigkeiten behandelten Material der Golgiapparat als helles Kanalsystem dargelegt wird, wie von Bergen angenommen.

In dieser Arbeit ist es mir gelungen, mittels der Kolatchevscher Osmiumimprägnationsmethode den Golgiapparat in den apokrinen Schweissdrüsenzellen prächtig darzustellen. Die Golgiapparate der apokrinen Schweissdrüsenzellen gehören, wie von Melczer angegeben, dem komplexen Typus nach Hirschlet an; sie bestehen aus mehr oder weniger geschlängerten, miteinander anastomosierenden, tief schwarz imprägnierten Strängen, sogenannter osmiophiler Substanz, zeigen einen knäuelartigen Bau. Sie stellen im ganzen die gut umgeschlossenen rundlichen Körper dar, welche nahezu gleich gross wie der Kern derselben Drüsenzellen sind. Der Innenraum des Golgiapparates ist als Ganzes schwach imprägniert; er scheint aus der sogenannten osmiophoben Substanz zu bestehen (Internum nach Hirsch (1939)), aber er enthält immer vakuolenartige und kanälchenartige helle Stellen, welche letztere entlang den osmiophilen Strängen (Externum nach $\mathrm{Hirsch}$ ) gestreckt sind, so dass der Intimbau des Golgiapparates kompliziert ist. Der Golgiapparat befindet sich immer oberhalb des Kerns, nämlich zwischen dem Kern und der freien Oberfläche der Zelle; bei den zylindrischen Zellen liegt er vom Kern etwas entfernt, dabei treten zwischen dem Kern und Golgiapparat Sekretgranula auf (Fig. ro-16). Bei den niedrigen, kubischen oder platten Zellen liegt der Golgiapparat direkt der Kernmembran an (Fig. 17), oft sogar platt-gedrückt. Dabei kommt er nicht selten in einer Seite oder in beiden Seiten des Kerns vor (Fig. I8).

Für die Beobachtung der Beziehung des Golgiapparates zur Sekretgranula sind die Kolat che v-Präparate, welche mit Kull'scher Färbung gefärbt sind, sehr geeignet, weil die Sekretgranula ohne Färbung oft schwer sichtbar sind. Die Sekretgranula werden, wie oben bei der Beschreibung der Mitochondrien aufmerksam gemacht, auf Kosten der Mitochondrien gebildet. Dass der Golgiapparat dabei keine wichtige Rolle zu spielen scheint, kann man bei der Beobachtung der Fig. IO, II, I 2 u. a. ohne weiteres ersehen. Die Sekretgranula werden, wie diese Figuren zeigen, unterhalb des Golgiapparates im Basalabschnitt der Zelle aus den Mitochondrien gebildet und wachsen 
allmählich. Dabei erfährt der Golgiapparat keine Veränderungen. Alsdann treten im Apikalabschnitt unmittelbar oberhalb des Golgiapparates die gröberen reifen Sekretgranula auf, welche, wie oben erwähnt, durch färberische Beschaffenheiten und durch den Gehalt von Fett und Pigment von den übrigen basalen Sekretgranula verschieden sind. Nun lokalisiert der

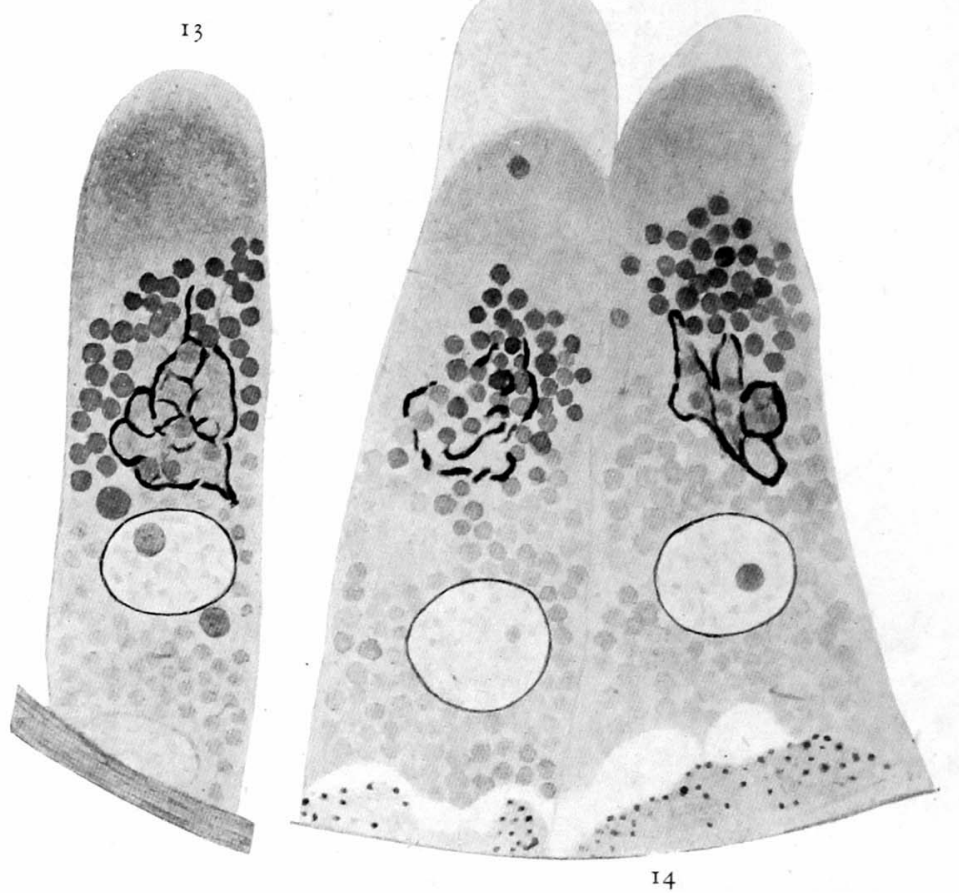

Fig. I3-14. Golgiapparat der apokrinen Drüsenzellen mit gröberen Sekretgranula. Drüsenzellen in Fig. I4 besitzen Sekretfortsatz. Kolats che v'sche Methode.

Vergrösserung wie bei Fig. I u. 2.

Golgiapparat sich im grossen ganzen zwischen den unreifen basalen Sekretgranula und den reifen apikalen; wir haben schon oben bei der Beschreibung der Mitochondrien und Sekretgranula den Golgiapparat als helles Golgifeld zwischen beiden Sekretgranulaarten bemerkt (s. S. 70). Aus obigen Befunden entsteht folgende Annahme, dass der Golgiapparat wahrscheinlich für die Reifung der Sekretgranula eine wichtige Rolle zu spielen scheint; die Sekretgranula dringen in den Golgiapparat ein, wo sie wahrscheinlich unter der Wirkung des Golgiapparates chemisch und physikochemisch verändern und in die reifen Sekretgranula umwandeln, dain treten sie von dem Golgiapparat hinaus, um im apikalen Abschnitt der Zelle, meistens oberhalb des Golgiapparates sich anzusammeln. Wie in der Fig. 10-14 ersichtlich, 
enthält der Golgiapparat innerhalb selbst die Sekretgranula in wechselnder Zahl, welche wahrscheinlich im Golgiapparat nach apikalwärts durchgehen. Die Beschaffenheiten solcher Sekretgranula stimmen mit den der reifen Sekretgranula überein. Weiterhin möchte ich annehmen, dass das Pigment und Fett in reifen Sekretgranula auch innerhalb des Golgiapparates geliefert werden.

Im Stadium, wenn die Drüsenzellen die Sekretfortsätze bilden, erscheinen oft am Golgiapparat merkliche Veränderungen, welche man in der Fig. I4, is und I6 bemerkt; die Sekretgranula innerhalb des Golgiapparates nehmen an Zahl beträchtlich zu, so dass die Stränge des Apparates erscheinen, als ob sie zwischen den Sekretgranula liegen, was oft bei den Drüsenzellen der verschiedenen Drüsen von Autoren wahrgenommen worden ist. Diese Befunde sprechen meiner Ansicht nach dafür, dass die Bildung der reifen Sekretgranula bei der Bildung des Sekretfortsatzes beträchtlich gehoben wird.

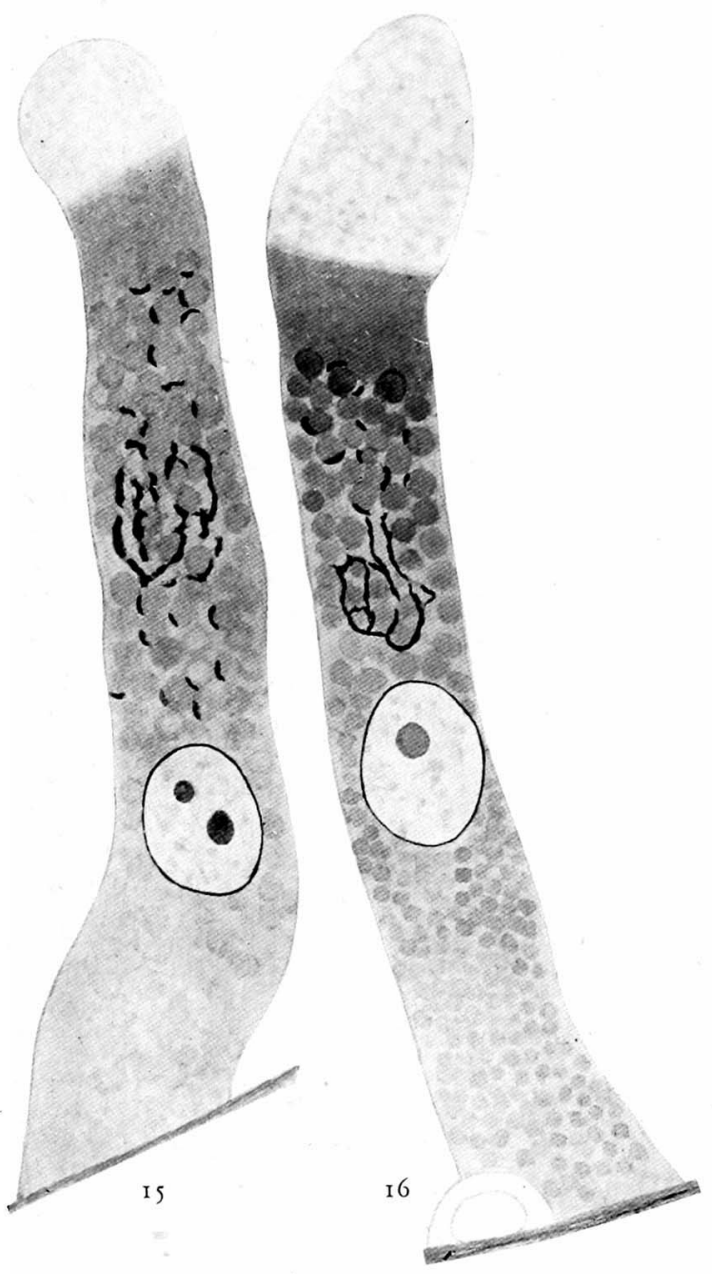

Fig. 15-16. Golgiapparat der apokrinen Drüsenzellen mit Sekretfortsatz und Sekretgranula. Kolatchev'sche Methode. Vergrösserung wie bei Fig. I u. 2.

Auf der Oberfläche der Sekretgranula schmiegt sich oft kurzes Stückchen des Apparates halbmondförmig an; dies spricht auch davon, dass der Golgiapparat zur Bildung der reifen Sekretgranula eine innige Beziehung besitzt. Aber es war mir nicht möglich, zu entscheiden, ob die Stückchen erschöpft werden und innerhalb der reifen Sekretgranula verschwinden oder als ,Golgi-Reste“ nach Hirsch (1939) übrig bleiben. 
Für die Beobachtung des negativen Bildes des Golgiapparates liefern die apokrinen Schweissdrüsenzellen das geeigneteste Material; in diesen Zellen kommt das Golgi-Negativ bei den Präparaten am schärfsten vor, welche mit Levi'scher, Regaud'scher Flüssigkeit und Zenker-Formol fixiert und mit Eisenhämatoxylin nach $\mathrm{Heidenhain} \mathrm{gefärbt} \mathrm{worden} \mathrm{sind} \mathrm{(Fig.}$ 2, 3, 4, 5, 6, 9, 21). Die Zytoplasmazone, welche von dem Golgiapparat eingenommen ist, wird dabei oberhalb des Kerns zwischen den reifen gröberen und kleineren Sekretgranula als ein rundlicher, granulaarmer, heller Hof wahrgenommen, den ich oben als ,Golgi-Feld“ bezeichnet habe. Innerhalb des

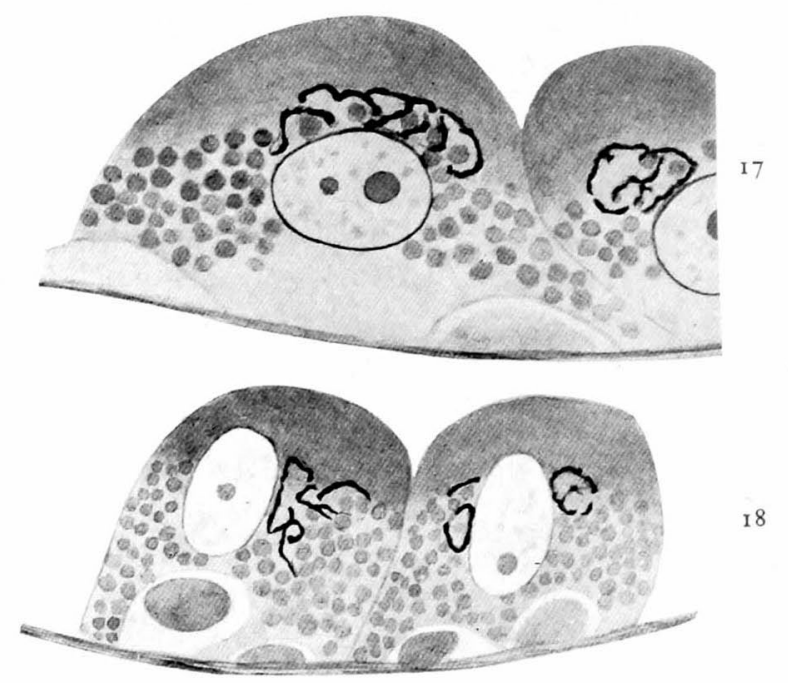

Fig. 17-18. Golgiapparat der niedrigen apokrinen Drüsenzellen mit Sekretgranula.

Kolatchev'sche Methode. Vergrösserung wie bei Fig. I u. 2.

Golgi-Feldes findet man meistens mehr oder weniger gebogene helle Kanälchen vor, welche zweifelohne den Strängen (osmiophiler Substanz) des Golgiapparates entsprechen.

\section{Fett, Pigment und Eisen in apokrinen Schweissdrüsenzellen.}

Dass die Schweissdrüsen im allgemeinen Fett sezernieren können, wurde von früher auf Grund der Tatsache vermutet, das der Schweiss der Handteller und Fusssohle, wo keine Talgdrüse sich befindet, wirklich Fett enthält. Über diese Frage hat Schiefferdecker (1922) unter Berücksichtigung der zahlreichen Literaturen erörtert. Nach seiner Zusammenfassung haben Unna (1898), Renaut (1899), Sata (I900), Ledermann (I901), Nicolas, Regaud und Favre (1921 a, b) u. a. die fettbildende Funktion und Fettsekretion der Schweissdrüsenzellen morphologisch nachgewiesen. Schief- 
ferdecker selbst kam zu der Schlussfolgerung, dass sowohl die apokrinen wie die ekkrinen Schweissdrüsen Fett zu sezernieren vermögen. Anderseits ist es seit Kölliker (1850) bekannt, dass die Schweissdrüsenzellen Pigmentkörnchen enthalten. Im Jahre I925 hat Homma zuerst an den Pigmentkörnchen in apokrinen Schweissdrüsenzellen der menschlichen Achselhaut oft die positive Eisenreaktion mit Turnbullsblaumethode gefunden. Durch Überblick der zahlreichen Abhandlungen kann man leicht erkennen, dass bei den apokrinen Schweissdrüsenzellen das Fett, Pigment und Eisen in einer innigen Beziehung zu stehen scheinen. Talke (1903) hat bei den apokrinen Schweissdrüsen der menschlichen Achselhaut gelbe, orange und bräunliche Pigmentkörnchen von verschiedener Grösse und Fettkörnchen im kolbig angeschwollenen Endabschnitt der dunkel vergrösserten sezernierenden Drüsenzellen gefunden. Er hat dabei angenommen, dass diese beiden Körnchen ins Drüsenlumen sezerniert werden. Nach seiner Angabe färben sich die Pigmentkörnchen mit Osmiumsäure intensiv braun an, doch werden sie mit Sudan III nicht gefärbt und durch Alkohol, Äther und Xylol nicht ausgezogen; also war die Fettnatur der Pigmentkörnchen ihm fraglich. Er hat deshalb die Fett- und Pigmentkörnchen als identische Bildungen nicht gefasst. Herzenberg (1927) hat auch bei den apokrinen Schweissdrüsen der menschlichen Achselhaut im distalen Abschnitt der Drüșenzellen die goldgelben, ockergelben und eosinophilen stark lichtbrechenden Körnchen gefunden, welch erstere in ca. 40\% der Fälle positive Eisenreaktion (nach Hueck) geben, während beide letztere sich der Eisenreaktion gegenüber refraktär verhalten. Aber die ockergelben und eosinophilen Granula zeigen positive Fettfärbung mit Sudan III oder Scharlachrot, so nahm He r z en berg bei diesen Lipoidgehalt an. Nách Herzenberg bestehen die eosinophilen Granula der Hauptsache nach aus Eiweisssubstanzen, also enthält das Sekret der apokrinen Schweissdrüse Eiweisssubstanzen, Lipoide und Eisen. Neuerdings hat Richter (1933) bei den apokrinen Schweissdrüsen der menschlichen Achselhaut das Ergebnis von Ho m ma bestätiget, dass die Pigmentkörnchen teilweise Eisen enthalten, so hat er das Pigment in apokrinen Schweissdrüsenzellen als Eisenpigment bezeichnet. Er hat angegeben, dass das Eisenpigment wenigstens zum Teil ins Sekret übergeht. Er hat ausserdem in allen Fällen verschiedene Menge von Fett in den apokrinen Schweissdrüsenzellen gefunden und festgestellt, dass die Fettropfen in ihrer Lokalisation mit dem Eisenpigment übereinstimmen. Nach Melczer (1935) kommen Pigmentkörnchen, welche nach Homma Eisen enthalten, zweifellos innerhalb des Golgiapparates vor. Aus obigen Ergebnissen der Autoren entstehen folgende Fragen, erstens ob das Fett, Pigment und Eisen besondere Granula bilden oder in denselben Granula enthalten sind und zweitens ob 
die drei Substanzen bei der Sekretion wirklich ausgeschieden werden. Die dritte Frage ist die Beziehung zwischen Sekretgranula und diesen drei Substanzen.

Ich habe oben bei der Beschreibung der Sekretgranula schon aufmerksam gemacht, dass im Apikalabschnitt der Zelle oberhalb des Golgiapparates eine Ansammelung der gröberen reifen Sekretgranula $\mathrm{zu}$ finden ist, welche Fett und Pigment enthalten. Bei den mit Levi'schem Gemisch fixierten Präparaten färben sich Sekretgranula, falls man mit Eisenhämatoxylin nach Heidenhain färbt, sämtlich dunkel bläulich und man kann ausserdem keine ungefärbt bleibende Pigment- und Fettgranula bemerken. Wenn man aber die Levi-Präparate ungefärbt beobachtet, so kann man im apikalen, durch reife gröbere Sekretgranula eingenommenen Abschnitt tief schwarz oder bräunlich schwarz osmierte, gröbere Granula wahrnehmen. Färbt man weiter die mit Formol fixierten Gefrierschnitte mit Sudan III nach Kawamura-Yasaki, so bemerkt man in derselben Lokalisation gröbere, rötlich gefärbte Granula. Aus obigen Befunden geht natürlich hervor, dass die im Endabschnitt der Zelle befindlichen gröberen, mit Eisenhämatoxylin intensiv färbbaren reifen Sekretgranula mit Fettsubstanz beladen sind. Die Schwärzung mit Osmiumsäure ist aber bei den Kolatchev-Präparaten nicht so intensiv wie bei den Levi-Präparaten, indem sie dabei nur bräunlich angefärbt werden. Diese Granula sind aber bei den mit Zenker-Formol fixierten Paraffinschnitten nicht aufgelöst worden; so kann man verstehen, dass sie Alkohol und Xylol gegenüber resistent sind. Sie sind, wie oben erwähnt, mit Eosin und Eisenhämatoxylin gut färbbar. Daraus kann man schliessen, dass sie hauptsächlich aus Eiweiss bestehen. Bei den Zenker-Formol fixierten und mit Eisenhämatoxylin gefärbten Schnitten sind die Sekretgranula, besonders apikale gröbere intensiv angefärbt, wie bei den Levi-Präparaten. Färbt man mit Zenker- Formol fixierte Schnitte mit Hämatoxylin (Ha n s e n)Eosin, so färben sich Sekretgranula im allgemeinen mit Eosin rot; aber oft erfolgt die Eosinfärbung schwach, so kann man erkennen, dass die im Apikalabschnitt vorhandenen gröberen Granula stark lichtbrechend sind und gelbliche Eigenfarbe besitzen. Daraus kann man verstehen, dass die reifen Sekretgranula eine gelbliche Eigenfarbe führen oder gelbes Pigment enthalten.

Aus obigen gesamten Ergebnissen bin ich zu folgender bemerkenswerten Schlussfolgerung gekommen, dass Fett und Pigment keine besondere Granula bilden, sondern dass sie in den im Apikalabschnitt befindlichen, reifen Sekretgranula, welche hauptsächlich aus Eiweisssubstanz bestehen, gebunden sind.

In der vorliegenden Untersuchung habe ich leider die Eisenreaktion nicht geprüft, doch ist es höchstwahrscheinlich, dass das Eisen in reifen 
Sekretgranula gebunden ist, wie nach Angaben von Autoren das Eisen in Pigmentkörnchen, welche nach meiner Untersuchung mit den reifen Sekretgranula identisch sind. Somit efgibt sich, dass die reifen Sekretgranula der apokrinen Schweissdrüsenzellen Fett, Pigment und zuweilen auch Eisen enthalten.

Wie oben berichtet, beteiligt sich der Golgiapparat an den Reifevorgängen der Sekretgranula ; daraus kann man wohl schliessen, dass das Fett, Pigment und Eisen innerhalb des Golgiapparates den Sekretgranula zuge-' fügt werden; die Sekretgranula scheinen somit innerhalb des Golgiapparates pigment-, fett- und eisenhaltig zu werden. Melczer (1935) hat auch innerhalb des Golgiapparates Pigmentkörnchen gefunden. Der Golgiapparat scheint also sich àn der Bildung von Fett, Pigment und Eisen in den apokrinen Schweissdrüsenzellen zu beteiligen.

$\mathrm{Da}$ das Fett, Pigment und Eisen in den reifen Sekretgranula gebunden sind, unterliegt es keinem Zweifel, dass sie zusammen mit den Sekretgranula ausgeschieden werden. Wir finden aber innerhalb der Sekretfortsätze niemals geformte Granula vor, so scheinen diese Substanzen auch in einem gelösten und ungeformten Zustand in die Sekretfortsätze überzugehen.

\section{Stäbchensaum an der freien Oberfläche der apokrinen Schweissdrüsenzellen.}

Ich habe in det vorliegenden Untersuchung an der freien Oberfläche der Drüsenzellen eine dem Kutikularsaum oder Stäbchensaum der Darmepithelien sehr ähnliche Bildung vorgefunden; diese Bildung besteht aus zahlreichen, äusserst feinen, auf der freien Zelloberfläche der Zelle vertikal stehenden, kurzen Stäbchen, welche mit Eisenhämatoxylin nach Heidenhain und Anilinfuchsin kaum angefärbt werden (Fig. I, 5, 6).

Kölliker ( 1850$)$ hat schon gleiche Bildung bei den Schweissdrüsenzellen beschrieben; er fand auf der Oberfläche der Zelle Cuticula, welche deutliche Streifung zeigt und erscheint, als ob sie von Porenkanälchen durchgezogen sei. Heynold (1874) hat an den Drüsenzellen der Achselschweissdrüsen nicht dicke Cuticula bemerkt. Nach Joseph (zit. nach Talke) ist die Cuticula bei Achseldrüse nicht, aber Ohrschmalzdrüse vorhanden. Talke (1903) hat sich geäussert, dass er bei den apokrinen Achselschweissdrüsen echte Kutikularbildung nicht beobachtet hat. Neuerdings hat Schaffer (1927) an der freien Oberfläche der Drüsenzellen der menschlichen Achselschweissdrüsen einen färbbaren Saum gefunden, welcher in gewissem Stadium zweifellos auftritt. Nach seiner Angabe besteht der Saum aus dicht gelagerten, färbbaren Körnchen. Somit scheint der färbbare 
Saum nach Schaffer mit der oben genannten Cuticula nicht identisch zu sein.

Nach meiner Beobachtung wird der Stäbchensaum der apokrinen Schweissdrüsenzellen bei der Fixerung mit Le vi'scher Flüssigkeit und K o latchev'scher Methode am besten erhalten. Er wird nur an den Zellen, welche noch nicht mit dem Sekretfortsatz versehen sind, gefunden. Beim Wachsen des Sekretfortsatzes fallen die Stäbchen, welche die Cuticula zusammensetzen, nach und nach $a b$, um an dem Sekretfortsatz gänzlich zu verschwinden. Der Stäbchensaum der Schweissdrüsenzellen ist in Vergleich mit dem der Darmepithelien viel schwächer gebildet, und gegenüber den Fixierungsflüssigkeiten minder resistent. In dieser Hinsicht ist er vielmehr dem Bürstensaum der Nierenepithelien ähnlich.

\section{Sekretionsmodus der apokrinen Schweissdrüsenzellen.}

Ich habe oben bei der Beschreibung der Sekretgranula das Vorkommen einer homogenen, dicht gebauten Zytoplasmazone zwischen der freien Oberfläche der Zelle und der Anhäufung der reifen Sekretgranula als eine wichtige Eigentümlichkeit dieser Drüsenzellen hervorgehoben. Diese Plasmazone scheint nach meiner Ansicht bei der apokrinen Sekretion eine wichtige Rolle zu spielen; sie bleibt im ganzen Verlauf der apokrinen Sekretion immer erhalten. Sie besitzt immer eine beträchtliche Dicke und färbt sich mit Farbstoffen deutlich; besonders kommt sie bei Kolatchev-Präparaten und Kolatchev-Kull-Präparaten als eine dunkle Zone auffallend zutage (Fig. I0-I8). Bei apokrinen Schweissdrüsen der Tiere haben Mis law sk y (1907) und Brinkmann (I9II) die gleiche Zone bemerkt. Nach Mislawsky ragt diese der Drüsenlichtung zugewandten, die fuchsinophilen Granula gänzlich entbehrten, homogenen Abschnitte der Zelle bei der apokrinen Sekretion ins Drüsenlumen vor und bilden homogene Kuppe, welche nach der Vergrösserung sich vom Zellkörper abschnürt. Es verhält sich etwas anders bei der apokrinen Schweissdrüse der menschlichen Achselhaut. Im Anfangsstadium der Sekretion wird der Zellkörper mit den Sekretgranula hochgradig gefüllt, dann ragt die betreffende homogene und dunkle Zytoplasmazone ins Drüsenlumen kuppelförmig vor, das Niveau der ursprünglichen, durch die Schlussleiste markierten Zelloberfläche etwas überschreitend (Fig. I I und I2). Aber solche vorragende dunkle Zytoplasmazone allein bildet nicht unmittelbar den Sekretfortsatz oder Zellkuppe. Wie in der Fig. I 3 wiedergegeben, kommt über dieser dunkel homogene Zone eine helle Schicht vor, welche allmählich nach lumenwärts wächst (Fig. I4), um schliesslich einen bläschenförmigen, ganz hellen Auswuchs (helles Bläschen) zu bilden (Fig. I5, I6). Auf diese Weise wird 
der Sekretfortsatz oder Zellkuppe ausgebildet. Die Grenze zwischen der dunkel homogenen Zytoplasmazone und dem hellen Bläschen ist immer gut ausgeprägt (Fig. I4, I 5, 16, 19). Die Gestalt der Sekretfortsätze ist verschieden (s. auch Fig. 19), aber die hellen bläschenförmigen Auswüchse sind

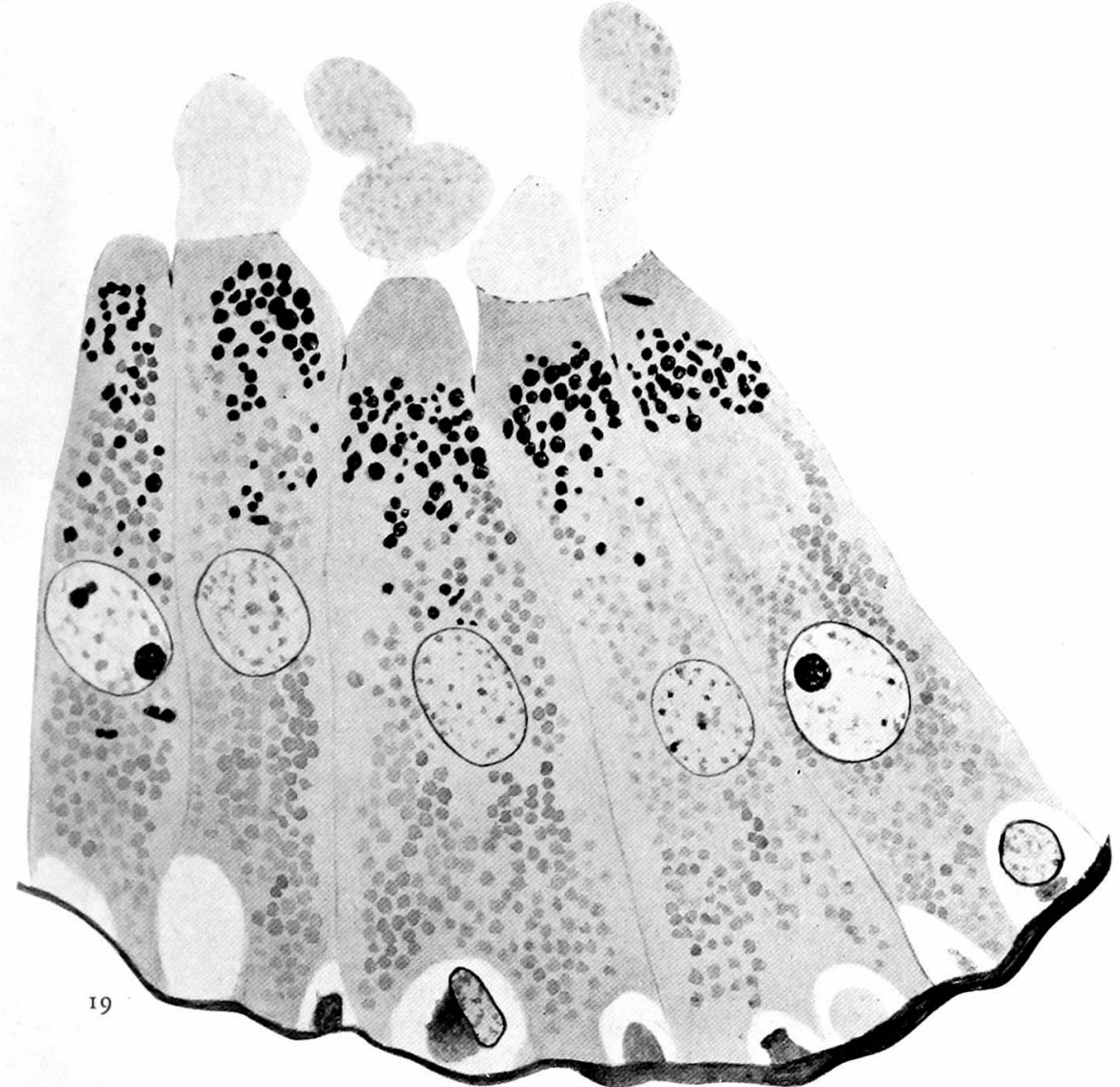

Fig. 19. Sekretfortsatz der apokrinen Drüsenzellen mit Sekretgranula. Fixiert mit Zenker-Formol, gefärbt mit Eisenhämatoxylin nach Heiden hain. Vergrösserung wie bei Fig. I u. 2.

immer von einer dünnen Membran umgeschlossen. Der Inhalt der Bläschen ist ganz hell und fein granulär oder alveolär. Es ist eine wichtige Tatsache, dass die bläschenförmigen Fortsätze niemals geformte Granula enthalten. Also muss man annehmen, dass die reifen Sekretgranula und darin enthaltenes Fett, Pigment und Eisen im gelösten Zustand die dunkel homogene Zytoplasmazone hindurch ins Sekretbläschen übergehen, darin man somit mikroskopisch die genannten chemischen Substanzen nicht mehr nachweisen kann. 
Die Sekretfortsätze wachsen allmählich, sie werden oft lang gestreckt, ragen ins Drüsenlumen weit hinein. Dabei verjüngt sich ihr Wurzelteil stielartig (Fig. 19). Die Abtrennung der Sekretfortsätze ins Drüsenlumen findet in dreierlei Weisen statt. Erstens wird die Membran der bläschenförmigen Auswüchse durahbrochen und der Inhalt fliesst ins Drüsenlumen hinein. Zweitens werden die Bläschen im ganzen von der homogenen Zytoplasmazone abgetrennt, dabei kommt oft an der Grenze zwischen dem bläschenförmigen Auswuchs und der homogenen Zytoplasmazone eine mit Eisenhämatoxylin gut färbbare Linie vor, welche stellenweise unterbrochen
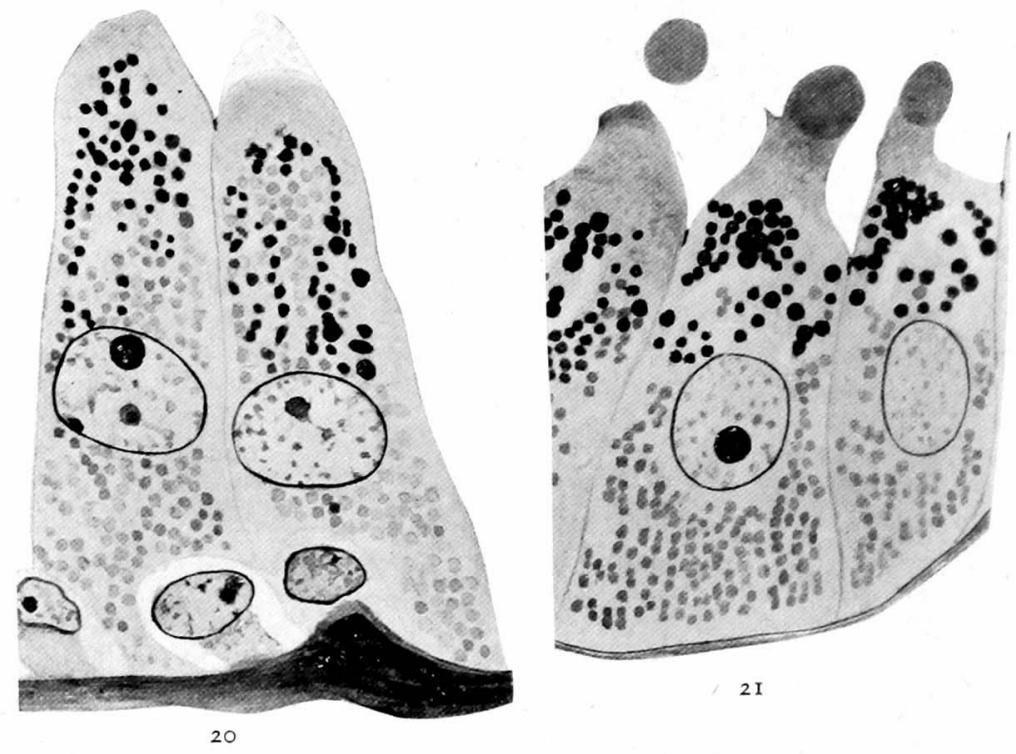

Fig. 20-21. Sekretfortsatz der apokrinen Drüsenzellen mit Sekretgranula. Fixierung, Färbung und Vergrösserung wie Fig. 19.

ist (Fig: 19). Drittens wandelt der bläschenförmige Auswuchs in ein dicht gebautes, dunkel färbbares, homogenes Kügelchen um, darauf wird dieses Kügelchen von der homogenen Zytoplasmazone abgetrennt (Fig. 2I). Bei jedem Falle bildet die dunkel homogene Zytoplasmazone nach der Entfernung der bläschenförmigen hellen Auswüchse neue Zelloberfläche (Fig. 20). Brinkmann (I9II) hat gleiche Resultate gewonnen; er hat sich geäussert : „Auf dieser Stelle sieht man, dass, während die Zellkuppe noch auf der Zelle sitzt, sich eine kompakte Protoplasmaschicht bildet ; wenn die Zellkuppe entfernt ist, bildet diese Schicht eine neue „Oberfläche.“

Nach meinen Ergebnissen besteht der sogenannte Sekretfortsatz aus der nach lumenwärts vorragenden, kuppenförmigen, dunklen, homogenen 
Zytoplasmazone und dem darüber sitzenden bläschenförmigen, hellen Auswuchs, der die von der Zelle bereitete Sekretmasse enthält. Bei der normalen apokrinen Sekretion trennt sich nur dieser bläschenförmige Auswuchs ins Drüsenlumen ab und die dunkle homogene Zytoplasmazone wird kaum zerstört. Daraus möchte ich schliessen, dass bei den normal funktionierenden apokrinen Schweissdrüsenzellen, im Gegensatz zur Meinung von bisherigen Autoren, der Zytoplasmaverlust nach der apokrinen Sekretion nicht bemerkenswert sei. Es kann aber nicht gänzlich ausgeschlossen werden, dass bei stark gesteigerter Funktion der Verlust der dunkel homogenen apikalen Zytoplasmazone erfolgt und die reifen Sekretgranula im geformten, gut färbbaren Zustand ins Drüsenlumen übergehen.

\section{Mitose, Amitose und Mehrkernigkeit der apokrinen Schweissdrüsenzellen.}

Talke (1903) hat bei den apokrinen Schweissdrüesn der menschlichen Achselhaut die Mitose häufig bemerkt, aber die Amitose kommt nach seiner Beobachtung nicht vor. Mislawsky (1909) hat bei der Unterkieferdrüse von Kaninchen Drüsenzellen mit 4-6 Kernen gefunden, welche dyrch Mitose hervorgerufen werden. Er fand dabei nur wenige Amitose. Brinkmann (1908) hat bei der Rückendrüse von Dicotyles nur zweimal Mitose wahrgenommen, er (I III) hat dagegen bei den Hautdrüsen von Säugetieren nur Amitose, nicht Mitose wahrgenommen, welche die Zellteilung nach sich zieht. $\operatorname{Er}(1923 / 24)$ hat weiter bei derapokrinen Hautdrüse von Wiederkäuer die Drüsenzelle mit 22 Kernen gefunden. Schaffer (1927) hat bei apokrinen Schweissdrüsen der menschlichen Achselhaut, wie Brinkmann (1908) angegeben, äusserst selten Mitose vorgefunden.

In der vorliegenden Untersuchung habe ich die zweikernigen apokrinen Drüsenzellen nicht selten wahrgenommen, aber die Figur der Mitose (Fig. 22) nur zweimal und die das Vorkommen der Amitose hindeutende Figur nicht. Also scheinen die zweikernigen Zellen durch mitotische Kernteilung gebildet zu werden. Die Frage, ob solche zweikernige Drüsenzellen sich durch nachfolgende Zelleinteilung in zwei Zellen teilen oder nicht, konnte ich hier nicht sicherlich lösen. Die zwei mitotischen Kern-

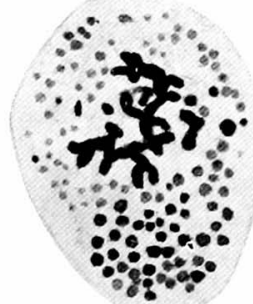

Fig. 22. Mitotische Kernteilung der apokrinen Drüsenzelle mit Sekretgranula. Fixierung, Färbung und Vergrösserung wie bei Fig. 20 u. 2 I. teilungsfiguren werden beide bei den mit Sekretgranula ausgefüllten Stapelzellen gefunden.

Bei den zweikernigen Drüsenzellen sind einzelne Kerne nahezu gleich 
gross, aber viel kleiner als bei den einkernigen Drüsenzellen, sie liegen meistenfalls in der Querrichtung dicht gedrängt nebeneinander. Der Golgiapparat solcher Drüsenzellen befindet sich, wie bei den einkernigen, oberhalb der Kerne bald einfach, bald in zwei Abschnitte gegliedert. Beim ersteren Fall ist der Apparat quer gestreckt (Fig. 25). Beim letzteren stellen
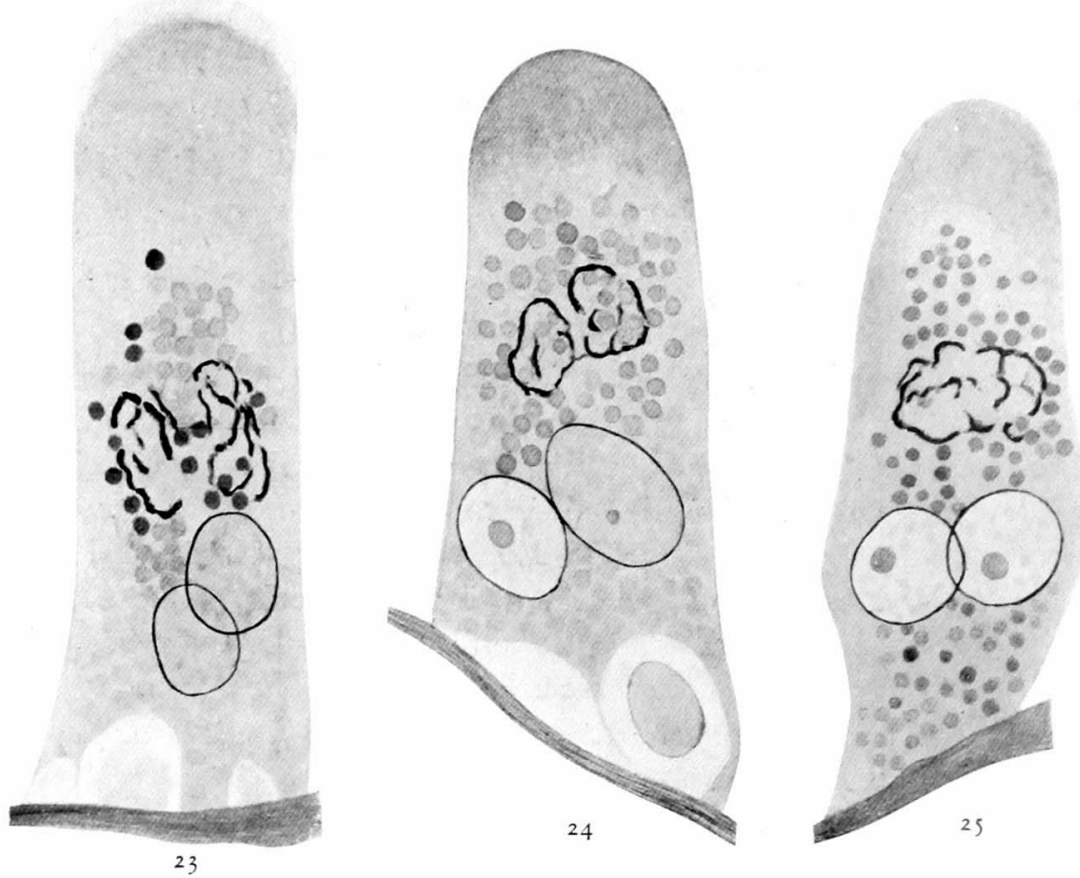

Fig. 23-25. Golgiapparat der zweikernigen apokrinen Drüsenzeilen. Kolatchev'sche Methode. Vergrösserung wie bei Fig. I u. 2.

zwei Abschnitte selbständige Apparate dar (Fig. 23), welche nebeneinander dicht gedrängt liegen und oft noch mit den Strängen zusammenhängen (Fig. 24). Also besitzen zwei Kerne bald einen Golgiapparat gemein, bald je einen besonderen Apparat. Nach Deineka (19I2) u. a. teilt sich der Golgiapparat bei der Mitose durch Diktiokinese auch in zwei Apparate ein, welche dem entgegengesetzten Pol der zwei Tochterkerne anliegen. Auf Grund dieser Untersuchung scheint es hier sich nicht um Mitose zu handeln, sondern vielmehr um Amitose. Bei der linken einkernigen Zelle in der Fig. 26 ist der Golgiapparat in zwei Abschnitte geteilt, bei der rechten hängen zwei Abschnitte noch durch einen Strang zusammen. Daraus kann man annehmen, dass der Golgiapparat unter Umständen vor der Teilung des Kerns sich in zwei Abschnitte teilen kann. Solche Teilungsweise des Golgiapparates 
kann man bei der mitotischen Teilung ebenso nicht erwarten. Aus den Befunden des Golgiapparates darf ich schliessen, dass bei den apokrinen Schweissdrüsenzellen ausser der Mitose noch amitotische Kernteilung vorkommen kann.

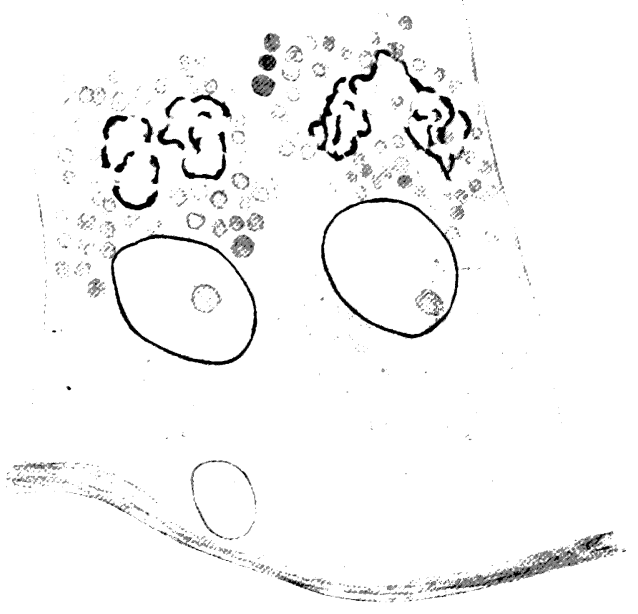

Fig. 26. Die in zwei Abschnitte geteilten Golgiapparate det einkernigen

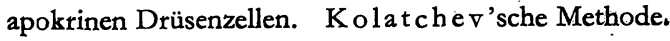
Vergrösserung wie bei Fig. I u. 2.

\section{Frage über den Abfall der Drüsenzellen.}

Bei der apokrinen Achseldrüse hat $\mathrm{T}$ a l ke (1903) den Zerfall der Drüsenzellen nach der Sekretion angenommen, obwohl er in Drüsenlumen abgefallene Drüsenzellen nicht wahrgenommen hat. Brinkman $\mathrm{n}$ hat bei den apokrinen Hautdrüsen von Tieren angenommen, dass die Drüsenzellen nach der Sekretion zerfallen können. Holmgren (1922) hat behauptet, dass die apokrinen Achseldrüsen zur holokrinen Sekretion neigen, weil bei ihnen viele ausgestossene Zellelemente in Drüsenlumen gefunden werden. Morioka (1935) hat bei der apokrinen Schweissdrüse der Āchselhaut von Individuen mit Osmidrosis die abgefallenen Drüsenzellen im Drüsenlumen wahrgenommen. Ich habe auch mit Kat o (194I) in der histologischen Arbeit über die apokrine Schweissdrüse in der Aussenhaut des Nasenflügels von Chinesen den Abfall der Drüsenzellen ins Drüsenlumen bemerkt. Schaffer (1927) hält aber den Abfall der Drüsenzellen für eine postmortale Veränderung der apokrinen Schweissdrüse, weil nach seiner Untersuchung die apokrinen Schweissdrüsen- 
zellen sich, wie von Schiefferdecker (I922) aufmerksam gemacht, nach dem Tod viel schneller als die ekkrinen Schweissdrüsenzellen verändern.

In der vorliegenden Untersuchung habe ich wieder bei den apokrinen Achseldrüsen nicht selten die abgefallenen Drüsenzellen im Drüsenlumen wahrgenommen. Die abgefallenen Drüsenzellen haben häufig eine hochgradige Veränderung des Zytoplasma gezeigt, während der Kern mit dem Kernkörperchen kaum verändert war. Das Zytoplasma solcher Zellen erschien hell, grob alveolär oder faserig, enthielt fast keine färbbare Granula. Die Gestalt der Zelle war oft unregelmässig, indem die Kontur zerstört wurde. Nach meiner Ansicht sprechen diese hochgradigen Veränderungen davon, dass diese Zellen nach dem Abfall lange Zeit im Drüsenlumen verweilt sind; ich habe solche hochgradig veränderten Zellen innerhalb des Drüsenepithels nicht gefunden. Aus obigen Befunden darf ich schliessen, dass der Abfall der Drüsenzellen nicht immer auf Kunstprodukt oder postmortaler Veränderung beruht.

\section{Zusammenfassung.}

Ich habe in der vorliegenden Untersuchung bei ${ }_{4} 4$ im iebendfrischen Zustand fixierten Achselhäuten, welche von erwachsenen Japanern mit Osmidrosis chirurgisch entfernt wurden, die apokrinen Schweissdrüsen zytologisch eingehend untersucht. In der Achselhaut von Individuen mit Osmidrosis stehen apokrinen Schweissdrüsen, wie durch meine vorgehende Arbeit festgestellt, in einem tätigen Zustand, so dass man dort die sekretorischen Veränderungen der apokrine Schweissdrüsenzellen zytologisch gut verfolgen kann. Somit habe ich in dieser Arbeit die Achselhäute von Individuen mit Osmidrosis als Untersuchungsmaterial gewählt. Wichtige Ergebnisse werden im folgenden zusammenfassend angegeben.

I) Die apokrinen Schweissdrüsenzellen sind im allgemeinen gross, verschieden geformt; die sogenannten zylindrischen Zellen stellen fünfbis sechsseitige Prismen dar. Das Zytoplasma ist immer dicht gebaut, mit verschiedenen Farben gut färbbar, so dass es im allgemeinen dunkel aussieht. Der Kern ist gewöhnlich rundlich, sieht hell aus und enthält in der Regel einen grossen rundlichen Nucleolus. Er liegt bei den zylindrischen Zellen meistens unterhalb der Mittelhöhe der Zelle. An den Kernen der apokrinen Schweissdrüsenzellen kann man im ganzen Verlauf der Sekretion fast keine bemerkenswerte Veränderung wahrnehmen.

2) Die Drüsenzellen können in hochzylindrische, niedrig kubische und mehr platte Zellen eingeteilt werden. Die hochzylindrischen Zellen sind am lebhaftesten sezernierende Zellen, die kubischen auch sezernierende, aber 
platte Zellen scheinen ruhende Zellen zu sein, obwohl sie immer gröbere Sekretgranula enthalten. Die Frage, ob diese drei Zellformen ineinander übergehen, nämlich verschiedene Sekretionszustände ein und derselben Zellart vertreten, oder ob sie besondere, selbständig funktionierende Zellarten sind, wird in der vorliegenden Untersuchung nicht gelöst.

3) Die Mitochondrien sind Stäbchen, Fäden und Granula, welche im grossen ganzen der Längsachse der Zelle parallel angeordnet sind. Die Drüsenzellen, welche zahlreiche Mitochondrien enthalten, kommen in den apokrinen Schweissdrüsen äusserst selten vor.

4) Die Mitochondrien wandeln in Sekretgranula um; dabei werden die stäbchenförmigen und fadenförmigen Mitochondrien zuerst in Doppelkörnchen und Körnchenketten umgeformt, dann in einzelne kleine Granula zerlegt, welche unter allmählicher Zunahme ihrer Grösse in Sekretgranula übergehen. Diese Umwandlung kommt im ganzen Zytoplasma fast gleichzeitig vor.

5) In den apokrinen Schweissdrüsen der menschlichen Achselhaut werden die mit Sekretgranula gefüllten Drüsenzellen (Granulazellen oder Stapelzellen) am häufigsten gefunden, bei denen wenige Mitochondrien zwischen den Sekretgranula besonders in der Zellbasis vorhanden sind.

6) Sekretgranula sind gewöhnlich rundlich, aber selten bemerkt man spindelförmige Sekretgranula. Ihre Grösse variiert nach den einzelnen Zellen und sogar in ein und derselben Zelle. Sie werden mit Levi's, Regaud's Flüssigkeit und Zenker- Formol gut fixiert, sind mit Eisenhämatoxylin nach Heidenhain, Anilinfuchsin und Eosin färbbar. Sie verteilen sich im ganzen Zytoplasma, das Golgifeld ausgenommen, gleichmässig dicht. Doch erreichen sie nie die freie Oberfläche der Zelle.

7) Die Granulazellen enthalten immer im apikalen Abschnitt oberhalb des Golgiapparates oder in der Umgebung desselben eine Anhäufung der gröberen, stark lichtbrechenden Sekretgranula, welche auch färberisch von übrigen Sekretgranula etwas verschieden sind. Bei Eisenhämatoxylinfärbung färben sie sich intensiver, sind gegen der Differenzierung mit Eisenalaun resistenter. Sie färben sich mit Eosin in verschiedenen Stärken und mit Kull'scher Färbung dunkel rötlich, gegenüber der Rotfärbung der übrigen Granula. Diese apikalen gröberen Granula scheinen also die reifen Sekretgranula zu sein.

8) Die reifen Sekretgranula bestehen hauptsächlich aus Eiweisssubstanz, enthalten aber Fett, Pigment und wahrscheinlich auch Eisen. Ich habe ausser den Sekretgranula keine besondere Pigment- und Fettkörnchen in den apokrinen Schweissdrüsenzellen wahrgenommen, wie von bisherigen Autoren angegeben; also sind Fett, Pigment und Eisen in den reifen Sekret- 
granula gebunden vorhanden. Somit sollen diese chemische Substanzen mit den reifen Sekretgranula ausgeschieden werden.

9) Ich habe bei den apokrinen Schweissdrüsen aber niemals wahrgenommen, dass die Sekretgranula sich verflüssigen und das Zytoplasma mit Sekretvakuolen ausfüllen, wie es bei verschiedenen Drüsenarten gewöhnlich der Fall ist. Ausserdem erreichen die Sekretgranula, wie oben erwähnt, nie die freie Oberfläche der Zelle. Somit befindet sich zwischen den reifen Sekretgranula und der letzteren immer eine Sekretgranula entbehrte Zytoplasmazone, wo ebenso nur wenige Mitochondrien zu finden sind. Diese immer verhältnismässig breite Zytoplasmazone ist dicht gebaut, mit Farben stark färbbar, so dass sie dunkel und ganz homogen aussieht. Ich möchte obige zwei interessante Tatsachen als wichtige Besonderheiten der apokrinen Schweissdrüsenzellen hervorheben. Das Vorhandensein dieser besonderen Zytoplasmazone im Endabschnitt der Zelle hat mit der apokrinen Sekretion zu tun.

I0) Es ist mir gelungen, in den apokrinen Schweissdrüsenzellen, den Golgiapparat mit Kolatchevscher Methode darzustellen. Wie von Melczer (1935) beschrieben, gehört der Golgiapparat der apokrinen Schweissdrüsenzellen dem, ,komplexen Typus“" nach Hirschler an. Er stellt im Ganzen ein geschlossenes rundliches Körper dar, welches nahezu gleich gross wie der Kern der Drüsenzelle ist. An dem Golgiapparat findet man stark osmierte Stränge (osmiophile Substanz) vor, welche miteinander anastomosierend eine Knäuelstruktur zeigen. Diese Stränge schliessen immer den Apparat von aussen um (Externum nach $\mathrm{Hirsch}$ ). Das Innere des Apparates wird als Ganzes schwach osmiert (osmiophobe Substanz oder Internum nach Hirsch). Der Golgiapparat liegt bei den zylindrischen und kubischen Zellen in der Regel oberhalb des Kerns, bei den platten Zellen oft in einer Seite oder in beiden Seiten des Kerns.

I I) Die Bildung der Sekretgranula findet unterhalb des Golgiapparates auf Kosten Mitochondrien statt, so scheint der Apparat für die Sekretgranulabildung nichts zu tun zu haben. Der Golgiapparat befindet sich zwischen den apikalen reifen Sekretgranula und den basalen jüngeren und beteiligt sich an die Reifung der Sekretgranula; die jüngeren Sekretgranula werden innerhalb des Golgiapparates unter der Wirkung desselben reif und sammeln sich als reife Sekretgranula im Apikalabschnitt an. Die reifen Sekretgranula finden sich in wechselnder Zahl innerhalb des Golgiapparates. Es scheint mir auch möglich, dass das Fett, Pigment und Eisen, welche an reifen Sekretgranula gebunden sind, innerhalb des Golgiapparates den Sekretgranula zugefügt werden.

I2) Der Golgiapparat der apokrinen Schweissdrüsenzellen verändert 
kaum seine Gestalt während der Sekretgranulabildung, aber im Stadium der erhöhten Sekretfortsatzbildung steigt die Bildung der reifen Sekretgranula empor; dabei erkennt man oft, dass die Elemente des Golgiapparates sich als kleine Stückchen halbmondförmig auf den reifen Sekretgranula anschmiegen. Es ist aber nicht zu entscheiden, ob solche Stückchen in die reifen Sekretgranula verschwinden oder als "Golgi-Reste" nach $\mathrm{Hirsch}$ übrigbleiben.

I3) Ich konnte bei den mit Levi'scher, Regaud'scher Flüssigkeit und Zenker-Formol fixierten Präparaten in den apokrinen Drüsenzellen negatives Bild des Golgiapparates (Golgi-Negativ) gut darstellen, welches zwischen den reifen und jüngeren Sekretgranula als rundlicher, nur wenige Mitochondrien oder Sekretgranula führender heller Hof (Golgifeld) zutage kommt. Innerhalb dieses Hofes findet man immer helle Kanälchen vor.

I4) Die eben unter 9) beschriebene, dunkle und homogene Zytoplasmazone im Endabschnitt der Drüsenzellen spielt im ganzen Verlauf der apokrinen Sekretion eine wichtige Rolle. Wird der Zelleib mit Sekretgranula ausgefüllt, ragt diese Zytoplasmazone ins Drüsenlumen kuppelförmig vor. Aber dies bildet allein den Sekretfortsatz oder Zellkuppe von Autoren nicht. Über diese vorragende dunkle Zytoplasmazone kommt weiter eine helle Schicht zustande, welche allmählich nach lumenwärts wächst, um schliesslich einen bläschenartigen, ganz hellen Auswuchs auszubilden. Auf diese Weise wird der Sekretfortsatz oder die Zellkuppe gebildet; er besteht also aus der kuppelförmig vorragenden dunklen Zytoplasmazone und dem darüber entwickelten bläschenartigen hellen Auswuchs. Die Grenze zwischen beiden Abschnitten ist immer scharf. Die bläschenförmigen Auswüchse sind von einem dünnen Oberflächenhäutchen umgeschlossen, deren Inhalt nichts anderes als die Sekretmasse ist. Der Inhalt sieht ganz hell aus, ist fein granuliert oder alveolär und vermengt keine geformte Granula. Also gehen die reifen Sekretgranula im geformten Zustand nicht in den Sekretfortsatz über. Wie eben unter 9) beschrieben, treten in den apokrinen Schweissdrüsenzellen niemals die Sekretvakuolen infolge der Verflüssigung der Sekretgranula auf. Somit muss man annehmen, dass die reifen Sekretgranula, einschliesslich des daran gebundenen Fettes, Pigments und Eisens, nach und nach aufgelöst und ohne Sekretvakuolenbildung die dunkle Zytoplasmazone hindurch in den bläschenförmigen Auswuchs ausgeschieden werden. Bei den apokrinen Schweissdrüsen findet die Ausscheidung der geformten färbbaren Sekretgranula gewöhnlich nicht statt.

15) Die Abtrennung der Sekretfortsätze erfolgt in folgenden dreierlei Weisen : Erstens wird das Oberflächenhäutchen der bläschenförmigen Auswüchse in einer Stelle durchbrochen und der Inhalt, nämlich die Sekretmasse fliesst ins Drüsenlumen aus. Zweitens wird der bläschenartige Auswuchs 
als Ganzes von der dunklen Zytoplasmazone abgetrennt; dabei tritt oft an der Grenzfläche des bläschenförmigen Auswuchses und der dunklen Zytoplasmaszone eine mit Eisenhämatoxylin färbbare Demarkationslinie auf. Drittens kondensiert sich der bläschenartige helle Auswuchs zu einem kompakten homogenen, dunkel gefärbten Kügelchen, welches dann im ganzen abgetrennt wird. In jedem Falle bildet die dunkle und homogene Zytoplasmazone neue Zelloberfläche.

16) Gewöhnlich wird bei der apokrinen Sekretion der Schweissdrüse nur der bläschenartige Auswuchs, in dem sich in Drüsenzelle gebildete Sekretmasse ansammelt, ins Drüsenlumen abgetrennt und die homogene Zytoplasmazone wird kaum zerstört, so soll der Zytoplasmaverlust nach der apokrinen Sekretion, im Gegensatz zur Anschauung von bisherigen Autoren, bei den apokrinen Schweissdrüsenzellen sehr leichtgradig sein. Aber solche Fälle werden nicht gänzlich ausgeschlossen, bei denen die homogene Zytoplasmazone zusammen mit dem bläschenförmigen Auswuchs zerstört und die färbbaren reifen Sekretgranula begleitend ins Drüsenlumen ausgeschieden wird.

17) Auf der freien Oberfläche der Drüsenzelle ist oft ein schwacher Stäbchensaum zu bemerken, welcher aus den äusserst feinen, schwer färbbaren, auf der Oberfläche der Zelle vertikal stehenden Stäbchen zusammengesetzt ist. Er scheint gegen den Fixierungsflüssigkeiten viel minder resistent zu sein als der Kutikularsaum der Darmepithelien. Beim Zustandekommen des Sekretfortsatzes wird er zerstört. Also ist er dem Bürstensaum der Nierenepithelien ähnlich beschaffen.

I8) In den apokrinen Schweissdrüsen kommen zweikernige Drüsenzellen nicht selten vor. Die mitotische Kernteilung wurde zweimal gefunden, aber Amitose niemals. Auf Grund der Beschaffenheiten des Golgiapparates in den zweikernigen Drüsenzellen muss man aber annehmen, dass die zweikernigen Drüsenzellen infolge der amitotischen Kernteilung entstehen.

I9) Im physiologischen Zustand können Drüsenzellen ins Drüsenlumen abfallen, was aber nie die holokrine Sekretion der apokrinen Schweissdrüsen deutet. Die abgefallenen Drüsenzellen fallen im Drüsenlumen einer hochgradigen Veränderung anheim.

Zum Schlusse spreche ich Herrn Prof. Dr. T. Taniguchi für seine stete Anregung und Herrn Dr. T. Ito für seine freundliche Leitung bei Ausführung dieser Arbeit meinen herzlichsten Dank aus. 


\section{Literaturverzeichnis.}

1) Bergen F. v., 1904. Zur Kenntnis gewisser Strukturbilder („Netzapparate”, „Saftkanälchen", „Trophospongien") im Protoplasma verschiedener Zellarten. Arch. mikr. Anat. Bd. 64. S. 498.

2) Brinkmann, A., 1908. Die Rückendrüse von Dicotyles. Anat. Heft. Bd. 36 . S. 283.

3) Derselbe, r9rx. Die Hautdrüsen der Säugetiere. Ergeb. Anat. u. Entw-gesch. Bd. 20. S. 1173 .

4) Derselbe, 1923/24. Nachlese $\mathrm{zu}$ meinen Hautdrüsenuntersuchungen. Bergens Mus. Jarbok. i923/24. (zit. nach Hoepke).

5) Deineka, D., r9r 2. Der Netzapparat von Golgi in einigen Epithel- und Bindegewebszellen während der Ruhe und der Teilung. Anat. Anz. Bd. 4x. S. 289.

6) Ejima, S. und K. Muto, 1935. Über die Sekretionserscheinungen der Schweissdrüsenzellen von Pferd. Jikken-Igaku Zasshi. Bd. 19. S. 1735. (Japanisch).

7) Herzenberg, H., 1927. Neue Beiträge zur Lehre von den apokrinen Schweissdrüsen. Virchows Arch. Bd. 266. S. 422.

8) Hirota, S., 1939. Statistical and experimental study of Osmidrosis. Seikai Zasshi. Bd. 58. S. 530. (Japanisch).

9) $\mathrm{H}$ irsch, G. Ch., r939. Form- und Stoffwechsel der Golgi-Körper. Protoplasma-Monographien Bd. I8. Berlin.

ro) Hoepke, H., I927. Die Haut.-Die Drüsen der Haut. Möllendorff's Handb. mikr. Anat. d. Mensch. 'Bd. III/I. S. 55. 1927.

II) Holmgren, E., 1922. Die Achseldrüsen des Menschen. Anat. Anz. Bd. 55. S. 553.

12) Homma, H., 1925. Uber positive Eisenbefunde in den Epithelien der apokrinen Schweissdrüsen menschlichef Axillarhaut. Arch. f. Dermatol. Bd. 148. S. 463 .

13) Joseph, M., r891. Über Schweiss- und Talgdrüsensekretion. Arch. Anat. u. Physiol. Physiol. Abt. Bd. 3. S. $8 \mathrm{I}$.

14) Kato, Sh. und K. Minamitani, r94I. Kurze Mitteilung über die apokrinen Schweissdrüsen in der Aussenhaut des Nasenflügels bei den Chinesen. Okajimas Fol. anat. jap. Bd. 20. S. 71 .

I5) Kölliker, A., I850. Mikroskopische Anatomie. Bd. 2. H. I. S. I59. (zit. nach Schaffer).

16) Melczer, N., I935. Über das Golgi-Kopsch'sche Binnennetz der menschlichen apokrinen Schweissdrüsenzellen. Dermat. Wochenschr. Bd. roo. S. 337.

17) Minamitani, K., r941. Zytologische und histologische Untersuchungen der Schweissdrüsen in menschlicher Achselhaut. Über das Vorkommen der besonderen Formen der apokrinen und ekkrinen Schweissdrüsen in Achselhaut von Japanern. Okajimas Fol. anat. jap. Bd. 20. S. 563 .

18) Mislawsky, A. N., r909. Zur Lehre von der sogenannten blasenförmigen Sekretion. Arch. mikr. Anat. Bd. 73. S. 68I.

19) Morioka, Y., r935. Studien über die Axillarschweissdrüsen bei Osmidrosis, besonders ihre morphologische Beobachtung. Mitt. d. med. Gesell. zu Okayama. Bd. 47 S. 3374. (Japanisch).

20) Nicolas J., Regaud, Cl. und M. Favre, rgrz. Surla fine structure des glandes sudoripares de l'homme particulièrement en ce qui concerne les mitochondries et les phenomènes de secrétion. C. R. de l'Assoc. des Anatomist. I4. Réun. Rennes, Bibliogr. anat. rgr2. Suppl. P. 20r. (zit. nach Schiefferdecker). 
2I) Richter, W., 1933. Beiträge zur normalen und pathologischen Anatomie der apokrinen Hautdrüsen des Menschen mit besonderer Berücksichtigung des Achselhöhlenorgans. Virchows Arch. Bd. 287. S. 277.

22) Sawada, H., I940. Über Mitochondrien in den Zellen der Haut und ihrex Anhangsorgane bei den Säugetieren. Jap. Zeitschr. f. Anat. Bd. I6. S. 203. (Japanisch).

23) Schaffer, J., 1927. Das Epithelgewebe. Möllendorff's Handb. d. mikr. Anat. d. Mensch. Bd. II/I. S. I.

24) Schiefferdecker, P., 1922. Die Hautdrüsen des Menschen und der Säugetiere, ihre biologische und rassenanatomische Bedeutung, sowie Muscularis sexualis. Zoologica. Heft. 72.

25) Talke, L., I903. Über die grossen Drüsen der Achselhöhlenhaut des Menschen. Arch. mikr. Anat. Bd. 6r. S. 537. 